\title{
Experimental and numerical behaviour of blind bolted flush endplate composite connections
}

\author{
Rumman Waqas ${ }^{\mathrm{a}, *}$, Brian $\mathrm{Uy}^{\mathrm{b}}$ and Huu-Tai Thai ${ }^{\mathrm{c}, \mathrm{d}}$ \\ a Centre for Infrastructure Engineering and Safety, School of Civil and Environmental Engineering, \\ The University of New South Wales, Sydney, NSW 2052, Australia \\ b School of Civil Engineering, The University of Sydney, Sydney, NSW 2006, Australia \\ ${ }^{c}$ School of Engineering and Mathematical Sciences, La Trobe University, Bundoora, VIC 3086, \\ Australia \\ ${ }^{d}$ Department of Infrastructure Engineering, The University of Melbourne, Parkville, VIC 3010, \\ Australia
}

\begin{abstract}
This research presents an experimental investigation and finite element model on the performance of composite beam-to-column flush end plate connections utilising blind bolts. Previous research recommended improvements to the design of these connections if they are required to withstand a low probability high consequence earthquake of a 1-in-2500 years return period. Therefore, two full-scale sub-assemblages of cruciform composite joints were tested under static and cyclic loading. The test results were used to establish the loaddisplacement characteristics of the connection. The experimental results demonstrated improved stiffness and strength when compared with a previous study. Two finite element models were developed and validated with the experimental data. Parametric studies were performed to investigate the influence of the thickness of equal angles, end plate thickness, shear connection ratio, reinforcement ratio and slab thickness on the connection behaviour.
\end{abstract}

Keywords: Composite beam-to-column connections, blind bolts, flush endplate, concretefilled steel tubular column

\footnotetext{
* Corresponding author. Tel.: +61 431083992

E-mail address: r.waqas@student.unsw.edu.au`
} 


\section{Introduction}

Concrete-filled steel tubular columns are extensively used in engineering practice due to excellent structural and constructional benefits such as high stiffness, ductility and improved fire resistance [1]. Wu et al. [2] suggested that the possibility of local buckling of the steel tube wall is reduced. The confined concrete also provides an increased strength as compared with the unconfined concrete due to the enhanced material properties resulting from the confinement.

Composite bolted end plate joints have been increasingly used in multi-storey buildings, primarily due to simplicity of their assembly and fabrication. Fig. 1 represents a typical blind bolted flush end plate composite joint which is composed of universal steel beams connected to a concrete-filled steel tubular (CFST) column using end plates with the help of blind bolts. A concrete slab is connected to the top flange of the steel beam with the help of shear studs.

A considerable number of experimental and analytical studies have been reported on composite joints during the past three decades [3-8]. However, these studies involved the use of standard bolts as blind bolting technique was not developed at that time. Therefore, experimental studies particularly involving blind bolting technique to connect endplate composite joint to CFST columns are very limited. Loh et al. [9] carried out experimental studies on five bolted flush end plate joints in which they investigated the effect of partial shear connection on the composite beam-column joint by varying the number of shear connectors and reinforcement. The experimental results concluded that the shear connection ratio has a significant effect on the performance of the connection. Thai et al. [10] carried out a series of experiments on composite joints using different shapes of columns and different types of endplates. Finite element models and analytical models were developed. The 
experimental results concluded that the use of extended endplates helps to considerably enhance the moment resistance and initial stiffness of the tested composite connection.

Prior to the 1994 Northridge and 1995 Kobe earthquake, rigid and fully welded connections were used in design. These events led to severe brittle fractures of fully welded connections. Therefore, increased research started to explore techniques to improve the seismic capacity of beam-to-column connections. The most effective substitutes are the use of semi-rigid connections which are considered favourable due to their ductility and energy dissipation capacity. However, difficulty arises on site due to access within the inside of CFST columns. To address this issue, blind bolts have been developed for use in Australia as shown in Fig. 2 which requires installation from one side only and are efficient, economical and a rapid solution to the problem.

Whilst the behaviour of blind bolted endplate connections under static loading has been extensively studied, only a few studies have focused on the behaviour of flush endplate connections under cyclic loading such as by [1, 11-15]. Extensive experimental investigation was performed by Wang et al. [13-15] to study the stiffness and strength degradation of beam-to-column flush endplate composite joints with square and circular hollow columns under cyclic loading.

Due to low seismicity experienced in Australia, it has been asserted that the Australian structures should be designed for a higher return period such as a 1-in-2500 years earthquake event. Mirza and Uy [1] performed full-scale tests on these connections for both static and cyclic loading scenarios. Their study demonstrated that the beam-to-column flush endplate connection demonstrated sufficient stiffness and strength for a 1-in-500 years return period. However, it required further improvements to withstand an earthquake of a 1-in-2500 years return period. Therefore, an experimental study was performed with improvements in the 
previous design by Mirza and Uy [1] in order to investigate the load-displacement behaviour of these connections under static as well as cyclic loading using blind bolting technique. The finite element package ABAQUS was used to develop the finite element (FE) models that replicated the experiments very well. Parametric studies were also performed to have an indepth knowledge of the behaviour of these connections. The results from this study are expected to be helpful for the design of similar composite joints in engineering practice.

\section{Experimental programme}

\subsection{Specimen design and preparation}

The experiments were based on an economical design of two geometrically identical specimens S1 and S2 with full shear connection based on Eurocode 4 (EC4) [16]. The details are shown in Fig. 3 and Fig. 4 and summarised in Table 1. S1 is tested under static loading whilst S2 is tested under cyclic loading conditions. The specimen consisted of four steel beams made up of a universal beam section 610UB101 (Grade 300) connected to a square CFST column 300x300x10 (Grade 350) in a cruciform arrangement to simulate the internal regions of a composite frame.

Four 150x150x12 mm equal angles were welded to the steel tubular column as shown in Fig. 5. Four $12 \mathrm{~mm}$ thick endplates Grade 350 were welded to the ends of the four steel beam using $10 \mathrm{~mm}$ thick fillet welds. Each beam was then connected to the CFST column by means of six AJAX, M20, Grade 8.8 blind bolts, based on the recommendations by the AJAX Fasteners [17]. A total of 24 AJAX one side blind bolts was used. These bolts were tightened up to $380 \mathrm{Nm}$ torque. Fig. 2 presents the illustration for the installation of AJAX blind bolt. A $1600 \mathrm{~mm}$ wide, $3868 \mathrm{~mm}$ long and $120 \mathrm{~mm}$ deep reinforced concrete slab was supported by $1 \mathrm{~mm}$ thick Stramit Condeck profiled steel sheeting which was transversely arranged and welded using 16 shear connectors of $\phi 19 \times 100 \mathrm{~mm}$ as shown in Fig. 6. Six shear studs were 
placed on each of the primary beams while two on each of the secondary beams to achieve a fully composite action. The main reinforcement consisted of $8 \phi 12$ steel bars were uniformly spaced in a single layer for the tensile reinforcement of the slab.

\subsection{Material properties}

Standard tensile tests were performed to determine the mechanical properties of structural steel material on coupons cut from the flange and web of the steel beams, endplates, equal angles, blind bolts and reinforcing bars. These results are summarised in Table 2 and their stress-strain relationships are plotted in Fig. 7. Normal strength concrete was used to cast the concrete slab and concrete filled inside steel column. Standard cylinder compression test was performed to determine the compressive strength of concrete whilst the splitting cylinder test was conducted to determine the indirect tensile strength of concrete. Based on these tests, the average values of compressive strength and indirect tensile strength of concrete at 28 days were 52.8 MPa and 4.6 MPa, respectively.

\subsection{Test set-up and loading procedure}

Fig. 8 shows a general arrangement of the test set up in the loading frame. The beam ends were supported using a roller and pinned bearing at $1.68 \mathrm{~m}$ away from the column surface. A nominal vertical load was applied at the top of CFST column using a hydraulic actuator which was positioned at the top girder of the testing frame. Moment at the connection can be easily determined by multiplying the lever arm with the reaction force. Two hydraulic jacks with $500 \mathrm{kN}$ capacity each were used to load the specimen vertically using displacement control method.

\subsection{Instrumentation}


Various measurement devices were used to record the relevant parameters that are useful to understand the behaviour of the system. These instruments were strain gauges, Linear Variable Displacement Transducer (LVDT) and inclinometers. In order to depict the strain profile in structural steel materials, strain gauges were installed on the reinforcement and steel beam web and flanges where high levels of stresses were expected as illustrated in Fig. 9.

Two inclinometers were mounted on the two ends of the steel beam one at the centre of the web close to the face of the column and fourth one on the column at the centre of the face of the column to measure the rotation of the joint. Each specimen was equipped with 11 LVDT's which were installed at various locations on the specimen to measure the relative slip between the concrete slab and steel beam, the transverse deformation of endplates. LVDTs were also placed at midpoint and the total mid span and vertical end deflection of the beam as shown in Fig. 10.

\section{Experimental results and discussion}

\subsection{General observations}

\subsubsection{Static loading experiment $S 1$}

The general deformation of specimen 1 is presented in Fig. 11. It can be observed that both tested joints suffered satisfactory rotations and failed in a ductile manner. No failure in blind bolts, shear studs or steel column wall was observed. No slip between the steel beam and concrete slab occurred as the specimens were designed to have a full shear connection.

A few barely visible cracks started to appear along the side of the slab towards the East and West of the specimen as shown in Fig. 11(a). As load kept on increasing gradually, several fine cracks kept on appearing especially around the mid span of the slab and along the edges 
close to the connection region. Detachment of the profiled steel decking from concrete slab was observed which was specifically prominent on all corners of the slab. Cracking in shear was also observed on both the North and South sides of the specimen as shown in Fig. 11(b). Finally, at the load level of $352 \mathrm{kN}$, a big crack in the concrete slab occurred that became the reason for the failure of the specimen as shown in Fig. 11(c) and (d). The load-displacement relationship of S1 is presented in Fig. 12.

\subsubsection{Cyclic loading experiment $S 2$}

The AISC loading protocol [18] as shown in Fig. 13 was used. From previous studies by Maenpaa [19] for a 2500 year return period scenario, only $30 \%$ of load reversal occurred in the worst scenario in Australia. Therefore, only $30 \%$ of the load was applied in tension. Cyclic loading was applied at the two beam ends using two hydraulic actuators of $500 \mathrm{kN}$ capacity each in compression and $250 \mathrm{kN}$ capacity each in tension. In the beginning, extremely fine cracks began to appear across the width of the slab as shown in Fig. 14(a). Debonding between the metal decking and concrete slab was quite evident as shown in Fig. 14(b). The cracks started to become more prominent and widespread across the slab in the area close to the connection region after $200 \mathrm{kN}$ as shown in Fig. 14(c). The specimen was loaded up to $\mathrm{kN}$ indicating failure of the specimen. failure in compression. Finally, there was a huge noise due to cracking of the concrete slab at $356 \mathrm{kN}$. The load-displacement relationship of S1 is presented in Fig. 15.

\subsection{Failure modes}

The failure modes for both static and cyclic loading cases were very similar as shown in Figs. 16-18. The test results in terms of critical parameters are presented in Table 4. Test results. Both specimens were able to sustain satisfactory deformations at peak load as they failed in a ductile manner. In both cases, cracks initiated around the column surface and propagated 
towards the edges of the concrete slab following an inclined pattern. Cracking of the concrete slab occurred prior to the failure of the connection.

Broken rebars were clearly visible from the wide-open crack for S2 while S1 was further knocked down to confirm the failure of rebar which is shown in Fig. 11 and Fig. 14. This occurred due to the yielding of reinforcement embedded in the concrete slab. The load versus strain relationship for steel beam and reinforcement are plotted in Figs. 19-21. The yield strains were calculated using relevant material test data from coupon samples and were plotted against the strain profile curves. The strain gauge readings show that rebars embedded in the concrete positioned in the middle exceeded the yield strain obtained from the tensile test results as shown in Fig. 19. The load transfer occurred from rebars to the tension part of the column as the yielding of rebars occurred first, followed by cracking of the concrete slab and bending of the endplate.

Based on the tensile test results presented in Table 2 earlier, Fig. 20(a) and (b) show that strains in the top and bottom flange were much lower than the yield strains. Fig. 21 shows some portions of the web experiencing tensile strain while some portions experiencing compressive strain. No yielding of steel beam web or flanges occurred as indicated in Fig. 20 and Fig. 21. The deformation of the top region of endplate at the bolt row close to the concrete slab occurred almost $11 \mathrm{~mm}$ on both sides. However, the part of endplate at the bolt row farthest from the concrete slab remained perfectly intact.

\section{Finite element modelling}

\subsection{General description}

The composite beam-to-column connection was simulated using ABAQUS software to study the behaviour in detail. A general layout of FE model is presented in Fig. 22. 


\subsection{Material properties}

\subsubsection{Concrete for monolithic behaviour}

For unconfined concrete, the model presented by Carreira and Chu [20] was used to describe the elastic-plastic behaviour of the compression region of the concrete as shown in Fig. 23(a). The model is expressed by the following equations, and compression is assumed to be linearly elastic up to $0.4 f_{c}^{\prime}$.

$$
\begin{aligned}
& \left.\sigma_{c}=\frac{f_{c}^{\prime} \gamma\left(\varepsilon_{c} / \varepsilon_{c}^{\prime}\right)}{\gamma-1+\left(\varepsilon_{c} / \varepsilon_{c}^{\prime}\right)^{\gamma}}\right] \\
& \gamma=\left[\frac{f_{c}^{\prime}}{32.4}\right]+1.55
\end{aligned}
$$

For confined concrete, the model presented by Tao et al. [21] was used which is presented in Fig. 24(a). The tensile behaviour is supposed to rise linearly up to concrete cracking at the tensile strength and then decreases to zero with the tension stiffening effect as reported by Thai et al. [22]. Compressive damage was ignored in the analysis as the failure mode detected in the experiment was cracking of the concrete slab in tension rather than crushing of the concrete in compression.

\subsubsection{Concrete for cyclic behaviour}

To simulate the concrete behaviour under cyclic loading, material constitutive laws were used for damage mechanics as discussed by Li et al.[23]. In this analysis, the unilateral damage law with two damage variables $\left(d_{c}\right.$ and $\left.d_{t}\right)$ is included to describe the concrete damage in compression and tension which are designated as $d_{c}$ and $d_{t}$, respectively. Fig. 24(b) presents the concrete behaviour in cyclic loading. In the beginning, the concrete acts linearly up to a tensile failure stress $f_{t}$. Beyond this stress, the concrete behaviour is defined by a post failure stress-strain relationship modelled by "Tension Damage" [22, 24]. During the transition of 
load from tension to compression, the elastic stiffness of concrete is degraded as the unloading response starts to decline. Similarly, the concrete damage plasticity model (CDP) is used when the loading is reversed from compression to tension. The concrete elastic stiffness degradation can be characterised by the tension damage variable $d_{t}$ and compression damage variable $d_{c}$ as shown in Eqs. (3) and (4)

$$
\begin{aligned}
& E_{t}=\left(1-d_{t}\right) E_{0} \\
& E_{c}=\left(1-d_{c}\right) E_{0}
\end{aligned}
$$

The concrete damage variables are determined using Eqs. (5) and (6) as

$$
\begin{gathered}
d_{c}=1-\frac{\sigma_{c} / E_{0}}{\varepsilon_{c, p l}\left(1 / b_{c}-1\right)+{ }^{\sigma_{c}} / E_{0}} \\
d_{t}=1-\frac{\sigma_{t} / E_{0}}{{ }_{t, p l}\left(1 / b_{t}-1\right)+{ }^{\sigma_{t}} / E_{0}}
\end{gathered}
$$

where $b_{c}$ and $b_{t}$ were taken as 0.7 and 0.1 as recommended by Birtel and Mark [25], $\varepsilon_{c, p l}$ and $\varepsilon_{t, p l}$ are the equivalent plastic strains. $\varepsilon_{c, i n}$ and $\varepsilon_{t, c k}$ represent the concrete inelastic strain in compression and concrete cracking strain in tension respectively.

\subsubsection{Steel properties}

The stress-strain relationship of different steel materials was defined using the data obtained from the standard tests listed in Table 2. Steel materials show initial elastic behaviour up to their yield points and followed by further yielding or strain hardening before fracture. The stress-strain relationships of these materials were converted into piecewise linear curves. Isotropic hardening was used for S1 under static loading, while kinematic hardening was used 
for S2 under cyclic loading. Fig. 24(b) illustrates the stress-strain relationships of the steel materials presented by Loh et al. [9] which is presented as a simple elastic-plastic model with strain hardening. Table 3 presents the stress and strain values for different steel materials as discussed by Mirza and Uy [1]. The mechanical behaviour for compression and tension is assumed to be similar.

\subsubsection{Geometry, element types and mesh}

Three-dimensional eight node element (C3D8R) was used for steel column, structure steel beam, concrete slab, blind bolts, and shear connectors. The rate of convergence was improved due to the use of eight nodes and three translational degrees of freedom. For the endplate, equal angle section and stiffeners, a three dimensional thirty-node quadratic brick element (C3D20R) was used due to the high accuracy and the ability to capture stress concentration. For modelling the profiled steel sheeting, a four-node shell element (S4R) was used because it is the most suitable element type for thin-walled steel structures. A threedimensional two-node truss element (T3D2) was used for the reinforcing steel. The mesh configuration used for each element was selected after conducting an extensive mesh sensitivity analysis beforehand.

\subsubsection{Contact properties, boundary and loading conditions}

Simply supported boundary conditions were applied. A nominal compressive load was applied vertically at the centre of the column using a reference point tied to the top surface of the column. In addition, load was applied $100 \mathrm{~mm}$ away from the edge of the concrete slab to simulate the vertical load applied at both ends. The load applied was calculated as the total reaction acting on the reference point. As blind bolts are tightened with enough pretension in practice, the same effect was achieved by applying a negative temperature to the shank of the blind bolt. 


\subsubsection{Model validation}

Two FE models developed in this study were verified against the experimental results. From Fig. 12, it can be observed that the FE model for specimen 1 accurately predicts the initial stiffness, ultimate load capacity and overall behaviour of the connection. These comparisons have been successfully made by the second and third authors [22] and this paper adopts their finite element model. Further comparisons against the static tests of Mirza and Uy [1] and Thai et al. [10] were made and comparably excellent agreement in terms of load deflection response as shown in Fig. 25. The failure modes were also quite similar as reported by [1] and [10]. The test results show considerably improved stiffness and strength as compared to previous studies by Mirza and Uy [1]. No failure of blind bolts or shear studs was observed as in previous studies and also blind bolts performed very well for both loading scenarios which demonstrates improvement in the connection's performance.

Fig. 15 demonstrates that the FEM for specimen 2 accurately predicts the critical parameters like initial stiffness, peak loads at every cycle in compression and tension, ultimate load and failure modes very well as shown in Figs. 25-27. However, the overall stiffness is not very well predicted. The reason for this discrepancy might be due to using tie constraints for defining the contact between the bolt head and infill concrete. As cyclic analysis takes a very long time to complete as compared to the static analysis, therefore, the reason for using embedded constraint instead of surface to surface constraint was only to simplify the model in order to save computational time. In addition, this study focuses on the global moment rotation behaviour of the connection and not the local crack in the concrete slab which makes it satisfactory for the validation. It is therefore suggested that these models are suitable to be adopted for parametric studies to study the effect of certain key parameters on the load- 
displacement behaviour of connections. The comparison between test results and FE results are presented in Table 5 .

\section{Parametric studies}

Parametric studies were carried out to further investigate the behaviour of the composite beam-to-column flush endplate connection in detail. The parameters selected for study are presented in Table 6. These parameters were selected due to their importance in contribution to the improvement in the strength and performance of connections.

\subsection{Parametric studies for S1 under static loading}

\subsubsection{Effect of flush end plate thickness}

Five different thicknesses were selected which are available in the market easily. These were $8,10,12,16$ and $20 \mathrm{~mm}$. Fig. 26(a) shows that an increase in the thickness of the flush end plates to 12,16 and $20 \mathrm{~mm}$ improves the initial stiffness and ultimate strength of the connection to 12,15 and $7 \%$. The endplate with 8 and $10 \mathrm{~mm}$ thickness reduces the initial stiffness and strength up to 13 and 7\%. For an $8 \mathrm{~mm}$ thickness endplate, the mode of failure was the fracture of the endplate whereas, for an increased thickness of endplate such as 10 to $20 \mathrm{~mm}$, the mode of failure was fracture of the reinforcement. Further increase in the thickness of flush end plate led to the fracture of blind bolt. It can be concluded that the thickness of flush end plate should not be too small so that fracture of the endplate can be avoided. On the other hand, the thickness of the flush end plate should not be very large so that the failure of blind bolt can be avoided. The finite element analysis results demonstrate that the configurations with $t_{e p} / d_{b}$ (thickness of endplate to diameter of bolt ratio) below 0.6 $\mathrm{mm}$ experienced failure of the flush endplate whereas, above $0.6 \mathrm{~mm}$ suffered blind bolt failure. Therefore, in order to achieve ductile behaviour of the composite joint the $t_{e p} / d_{b}$ ratio 
should be kept $0.6 \mathrm{~mm}, 60 \%$ of bolt diameter which is also mentioned in EC3 [29] and EC4 [19]. Another observation was that using an endplate thicker than the steel tubular column leads to the bending of the flange of steel tubular column as in the case of $16 \mathrm{~mm}$ and $20 \mathrm{~mm}$ thick flush endplates.

\subsubsection{Effect of equal angles thickness}

In this study, equal angles were proposed as a possibility to improve the connection's behaviour in terms of strength. Therefore, parametric studies on various thicknesses of equal angles were performed to explore their effect on the behaviour of these connections. These thicknesses were 8, 10, 12, 16 and $19 \mathrm{~mm}$. The results presented in Fig. 27(a) show an increase in ultimate strength of $8 \%$ when the thickness of equal angles is increased from 12 to $16 \mathrm{~mm}$. The value of ultimate load increases by $4 \%$ only when the thickness of the equal angle is increased further to $19 \mathrm{~mm}$. The ultimate strength decreases to 13 and $8 \%$ for 8 and $10 \mathrm{~mm}$ thick equal angle. The increase in thickness of equal angles has a negligible effect on the initial stiffness of the connection. It can be concluded that the use of equal angles on the side of steel tubular column does not make a significant contribution towards improving the stiffness and ultimate strength of the connection.

\subsubsection{Effect of reinforcement ratio}

Four different reinforcement ratios $(\mathrm{RR})$ were considered which were $8 \mathrm{~N} 12(0.5 \%), 8 \mathrm{~N} 16$ $(0.83 \%), 8 \mathrm{~N} 24(1.88 \%)$ and $8 \mathrm{~N} 28(2.5 \%)$. These ratios were calculated based on the tensile reinforcing area versus total slab cross sectional area. Fig. 28(a) shows that a very low value of reinforcement ratio results in limited strength and ductility. An increase in reinforcement ratios increases the initial stiffness, load capacity and ductility of the connection for $0.5 \%$ and $0.83 \%$. However, for $1.88 \%$ and $2.5 \%$, there is a slight increase in initial stiffness only. By using N16, N24 and N28 rebars, there is an $11 \%, 27 \%$ and $8 \%$ increase in ultimate load 
capacity of the connection. Moreover, an increase in reinforcement ratio limited the ductility and rotation capacity of the joint for $1.88 \%$ and $2.5 \%$ due to sudden failure of shear studs. Therefore, reinforcement should be very carefully designed as a greater number of reinforcements will not always be beneficial for the improvement of the connection's performance.

\subsubsection{Effect of shear connection ratio}

Four different degrees of shear connection were considered which are $35 \%, 50 \%, 100 \%$ and $140 \%$. The first two values represent partial shear connection, whereas the second two represent full shear connection. The respective load-displacement behaviour of S1 with these ratios is plotted in Fig. 29(a). It can be observed that the initial stiffness of the connection increases gradually with an increase in shear connection ratio from $35 \%$ to $100 \%$. However, there is a slight increase in ductility and ultimate load capacity for $100 \%$ and $140 \%$ full shear. A partial shear connection ratio of $35 \%$ shows limited strength and ductility. In this case the mode of failure is fracture of the shear studs. The ultimate load capacity reduces to 36 and 15 $\%$ with $35 \%$ and $50 \%$ shear connection ratios as shown in Fig. 29(a). The model with 35\% shear connection ratio demonstrated significant slip between the composite slab and steel beam. There was no slip at all in the case of $100 \%$ and $140 \%$ shear connection ratio. However, greater number of shear connection ratio led to limited rotation capacity and ductility of the joint.

\subsubsection{Effect of concrete slab depth}

In this study four different slab depths were selected which are 120, 150, 200 and $250 \mathrm{~mm}$. Fig. 30(a) shows that an increase in the depth of the concrete slab significantly increases the stiffness and strength of the connection. An increase of slab thickness of 150, 200 and 250 mm causes a 17, 24 and $35 \%$ increase in load capacity. However, failure was observed at a 
comparatively lower value of deflection when the thickness of the slab was increased respectively from 120 to $250 \mathrm{~mm}$.

\subsection{Parametric studies for $S 2$ under cyclic loading}

\subsubsection{Effect of various thicknesses of end plates}

Fig. 26(b) shows that an increase in the thickness of flush endplates gradually improves the initial stiffness and significantly improves the ultimate strength of the connection. For $t_{\mathrm{ep}} / \mathrm{d}_{\mathrm{b}}$ ratio below 0.6 , the mode of failure observed was yielding of endplate, whereas for $t_{\mathrm{ep}} / \mathrm{d}_{\mathrm{b}}$ ratio above 0.6 , the mode of failure changed to yielding of rebar and deformation of blind bolts. For a decrease in the thickness of endplate from 8 to $10 \mathrm{~mm}$, the corresponding reduction in stiffness and strength is 27 and $10 \%$, respectively. While an increase of 12,16 and $20 \mathrm{~mm}$ thickness causes 13, 11 and 7\% increase in initial stiffness and ultimate strength of the connection. The results show that an optimum value of flush endplates should be adopted in order to maximise the performance of these connections.

\subsubsection{Effect of various thicknesses of equal angles}

Fig. 27(b) exhibits the load versus deflection relationship of S2 with different thicknesses of equal angles. It shows that an increase in the thickness of equal angle does not have a significant effect on the initial stiffness of the connection but slightly improves the ultimate strength. For an increase in thickness of $8,10,12,14,16$ and $19 \mathrm{~mm}$ the increase in ultimate load is about $26,21,13,11,7$ and $4 \%$ only. The results demonstrate the use of equal angles is not quite beneficial to improve the behaviour of the connection. Therefore, some other technique should be adopted. 


\subsubsection{Effect of reinforcement ratio}

Four different reinforcement ratios were considered which were 8N12 (0.5\%), 8N16 (0.83\%), $8 \mathrm{~N} 24(1.88 \%)$ and $8 \mathrm{~N} 28(2.5 \%)$. Fig. $28(\mathrm{~b})$ shows that an increase in the area of reinforcement enhances the initial stiffness and load capacity of the connection. The results show that after a certain limit, further increase in reinforcement will not be as beneficial to the improvement of the connection's performance. A very low reinforcement ratio causes limited strength and ductility.

\subsubsection{Effect of shear connection ratio}

Four different degrees of shear connection ratio were considered which are $35 \%, 50 \%, 100 \%$ and $140 \%$. The results are presented in Fig. 29(b) which show that a decrease in shear connection ratio leads to a reduction in load capacity and ductility. A degree of shear connection of 35 and $50 \%$ causes 27 and $15 \%$ decrease in the load capacity. It was also observed that lower values of shear connection ratio cause an increase in deflection. The mode of failure in for $35 \%$ shear connection ratio was fracture of shear studs. It can be concluded that the shear connection ratio should at least be $50 \%$ to avoid fracture of shear studs before reinforcing bar failure.

\subsubsection{Effect of various thicknesses of concrete slab}

Fig. 30 (b) shows the load versus deflection curves for S2 with different thicknesses of concrete slab. The results show that an increase in slab thickness causes an increase in the load capacity. The initial stiffness did not change very significantly. However, the ductility increases by 3, 7 and $10 \%$ for 150, 200 and $250 \mathrm{~mm}$ depths of concrete slab, respectively. It is observed that cracking of concrete is reduced by using a greater thickness of concrete slab and can withstand greater ultimate loads under seismic conditions. The ultimate load capacity 
that the concrete slab can bear is increased to 10,16 and $21 \%$ when a concrete slab thickness of 150, 200 and $250 \mathrm{~mm}$ are used. Failure of shear connectors was observed when $250 \mathrm{~mm}$ thick concrete slab was used.

\section{Conclusions}

Full scale tests were performed on typical blind bolted, beam-to-column flush endplate connections which demonstrate sufficient strength and stiffness for use within medium rise buildings. The composite connection was tested under static and cyclic loading. The test results demonstrate that these semi-rigid composite connections can perform satisfactorily in terms of yielding, maximum strength capacity and ultimate displacement. The experimental results demonstrate a significantly improved stiffness and ultimate strength when compared with the previous study

The finite element models developed in this research show a reasonably good agreement with the test results in which the initial stiffness, ultimate strength and failure modes of the beamto-column connection for static and cyclic loading scenarios have been predicted with accuracy. Extensive parametric studies on various significant parameters were performed which help to gain an in-depth knowledge about the behaviour of these connections. Based on these results it is concluded that:

1. The thickness of the flush endplate should not be too small so that the endplate fracture can be avoided. On the other hand, it should not be too thick so that brittle failure of bolts in the connection zone can also be avoided. Thickness of endplate to bolt diameter ratio must be kept below 0.6 . The $12 \mathrm{~mm}$ thick endplate seem reasonable for the design of these connections. 
2. The use of equal angles on the sides of steel tubular column does not help to significantly enhance the performance of these connections. Therefore, some alternative method to increase the thickness of steel tubular column should be tested.

3. A thicker concrete slab reduces cracking of the concrete. A thicker slab not only increases the initial stiffness but also considerably improves the ultimate load capacity of the connection.

4. An increase in reinforcement ratio significantly improves the moment capacity of the connections. However, after a certain level it does not proves to be beneficial in regards to further improvements in the beam-to-column connection's strength.

5. It can be concluded that the shear connection ratio should at least be $50 \%$ to avoid fracture of shear studs before reinforcing bar failure. It helps to prevent the failure of shear connectors and improve the ductility of these connections.

6. It can be concluded that the improved design has an enhanced performance of the connection as compared with the previous experiment for both loading scenarios.

7. From parametric studies results, it is recommended that the thickness of the concrete slab and reinforcement ratio should be increased to an optimum value to further enhance the overall performance of these connections

8. Further studies should be attempted to make changes on the column capacity, including stiffeners and additional bolts. The possibility of using a viscoelastic material between the column surface and endplate can be studied as it might be beneficial to improve the flexibility of these connections under seismic loading conditions. 


\section{Acknowledgements}

The research work presented in this paper was financially supported by the Australian Research Council (ARC) Linkage grants (LP110200511) programme with industry partners Ajax Fasteners and Australian Tube Mills. The authors would like to express their gratitude to the funding sponsors for their generous support and would also like to acknowledge the University of New South Wales and the technical staff for assisting with the experimental investigations.

\section{References}

[1] O. Mirza and B. Uy, "Behaviour of composite beam-column flush end-plate connections subjected to low-probability, high-consequence loading," Engineering Structures, vol. 33, pp. 647-662, 2011.

[2] L.-Y. Wu, L.-L. Chung, S.-F. Tsai, T.-J. Shen, and G.-L. Huang, "Seismic behavior of bolted beam-to-column connections for concrete filled steel tube," Journal of Constructional Steel Research, vol. 61, no. 10, pp. 1387-1410, 2005.

[3] D. Anderson and A. A. Najafi, "Performance of composite connections: Major axis end plate joints," Journal of Constructional Steel Research, vol. 31, no. 1, pp. 31-57, 1994.

[4] J. M. Aribert and O. N. Dinga, "Modelling and experimental investigation of bolted flush end-plate composite beam-to-column joints," Composite Construction in Steel and Concrete, vol. 4, pp. 711-724, 2000.

[5] T. Q. Li, D. A. Nethercot, and B. S. Choo, "Behaviour of flush end-plate composite connections with unbalanced moment and variable shear/moment ratios- - I. Experimental behaviour," Journal of Constructional Steel Research, vol. 38, no. 2, pp. 125-164, 1996.

[6] J. Y. R. Liew, T. H. Teo, and N. E. Shanmugam, "Composite joints subject to reversal of loading-Part 1: experimental study," Journal of Constructional Steel Research, vol. 60, no. 2, pp. 221-246, 2004.

[7] J. Y. R. Liew, T. H. Teo, N. E. Shanmugam, and C. H. Yu, "Testing of steel-concrete composite connections and appraisal of results," Journal of Constructional Steel Research, vol. 56, pp. 117-150, 2000.

[8] L. Simões da Silva, R. D. Simões, and P. J. S. Cruz, "Experimental behaviour of endplate beam-to-column composite joints under monotonical loading," Engineering Structures, vol. 23, no. 11, pp. 1383-1409, 2001. 
[9] H. Y. Loh, B. Uy, and M. A. Bradford, "The effects of partial shear connection in composite flush end plate joints Part I-experimental study," Journal of Constructional Steel Research, vol. 62, pp. 378-390, 2006.

[10] H. T. Thai, B. Uy, Yamesri, and F. Aslani, "Behaviour of bolted endplate composite joints to square and circular CFST columns," Journal of Constructional Steel Research, vol. 131, pp. 68-82, 2017.

[11] I. S. Sheet, U. Gunasekaran, and G. A. MacRae, "Experimental investigation of CFT column to steel beam connections under cyclic loading," Journal of Constructional Steel Research, vol. 86, pp. 167-182, 2013.

[12] W. Tizani, Z. Y. Wang, and I. Hajirasouliha, "Hysteretic Performance of a New Blind Bolted Connection to Concrete Filled Columns under Cyclic Loading: An Experimental Investigation," vol. 46, pp. 535-546, 2013.

[13] J. Wang, H. Zhang, and Z. Jiang, "Seismic behavior of blind bolted end plate composite joints to CFTST columns," 2016.

[14] J. Wang, L. Zhang, and B. F. Spencer, "Seismic response of extended end plate joints to concrete-filled steel tubular columns," Engineering Structures, vol. 49, pp. 876892, 2013.

[15] J.-F. Wang, L.-H. Han, and B. Uy, "Hysteretic behaviour of flush end plate joints to concrete-filled steel tubular columns," Journal of Constructional Steel Research, vol. 65, no. 8-9, pp. 1644-1663, 2009.

[16] ENV. Eurocode 4: Design of composite steel and concrete structures-Part 1-1: General rules and rules for buildings, 1994.

[17] Ajax Fasteners. ONESIDE Technical Metric [Online]. Available: http://www.ajaxfast.com.au/page/oneside

[18] "'"Specification for Structural Steel Buildings" , American Institute of Steel Construction," 2005.

[19] D. Maenpaa, "Composite beam-column flush endplate connections subjected to low probability, high consequence loading," Thesis, School of Engineering, University of Western Sydney, Penrith, 2007.

[20] D. J. Carreira and K.-h. Chu, "Stress-Strain Relationship for Plain Concrete in Compression," ACI Journal Proceedings, vol. 82, no. 6, pp. 797-804, 1985.

[21] Z. Tao, Z.-B. Wang, and Q. Yu, "Finite element modelling of concrete-filled steel stub columns under axial compression," Journal of Constructional Steel Research, vol. 89, pp. 121-131, 2013.

[22] H.-T. Thai and B. Uy, "Finite element modelling of blind bolted composite joints," Journal of Constructional Steel Research, vol. 112, pp. 339-353, 2015. 
[23] D. Li, B. Uy, V. Patel, and F. Aslani, "Analysis and design of demountable embedded steel column base connections," Steel and Composite Structures, vol. 23, no. 3, pp. 303-315, 2017.

[24] A. Ali, D. Kim, and S. G. Cho, "Modelling of nonlinear cyclic load behaviour of Ishaped composite steel-concrete shear walls of nuclear power plants," Nuclear Engineering and Technology, vol. 45, no. 1, pp. 89-98, 2013.

[25] V. Birtel and P. Mark, "Parameterised Finite Element Modelling of RC Beam Shear Failure," Ababqus User's Conference, pp. 95-108, 2006.

\section{Table Captions}

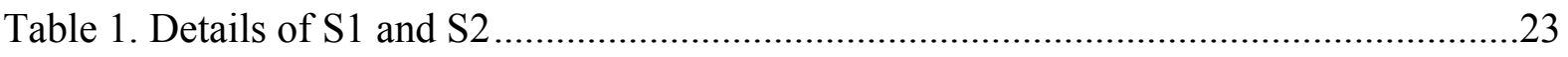

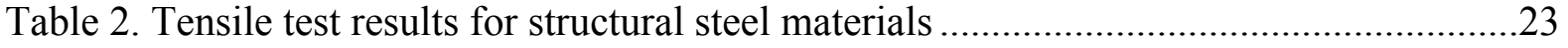

Table 3. Stress strain values for structural steel material ......................................................23

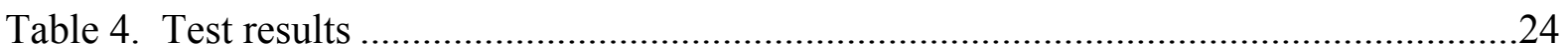

Table 5. Comparison between test results and predictions ...............................................24

Table 6. Parameters selected for parametric studies .........................................................24 
Table 1. Details of S1 and S2

\begin{tabular}{cll} 
No. & Member & Dimensions \\
\hline 1 & Steel column & SHS \\
2 & Concrete slab & $3868 \times 1600 \times 120$ \\
3 & Endplates & $270 \times 610 \times 12 \mathrm{~mm}$ \\
4 & Equal angles & $150 \times 150 \times 12 \mathrm{~mm}$ \\
5 & Ajax blind bolts & M20 AJAX \\
6 & Headed shear studs & $19 \times 100 \mathrm{~mm}$ \\
7 & Primary steel beam & $610 \mathrm{UB} 101 \times 1760$ \\
8 & Secondary steel beam & $610 \mathrm{UB} 101 \times 626$ \\
9 & Longitudinal reinforcing & $8 \mathrm{~N} 12$ \\
10 & Transverse reinforcing & $19 \mathrm{~N} 12$ \\
\hline
\end{tabular}

Table 2. Tensile test results for structural steel materials

\begin{tabular}{llll}
\hline Structural steel & $\begin{array}{l}\text { Yield stress } \\
(\mathrm{MPa})\end{array}$ & $\begin{array}{l}\text { Ultimate stress } \\
(\mathrm{MPa})\end{array}$ & $\begin{array}{l}\text { Elongation at fracture } \\
(\%)\end{array}$ \\
\hline Steel beam web & 380 & 508 & 27 \\
Steel beam flange & 325 & 483 & 30 \\
Steel column & 485 & 552 & 28 \\
Endplate & 367 & 499 & 23 \\
Reinforcement & 530 & 640 & 15 \\
M20 AJAX bolt & 820 & 966 & 30 \\
\hline
\end{tabular}

Table 3. Stress strain values for structural steel material

\begin{tabular}{llll}
\hline Element & $\sigma_{\mathrm{us}}$ & $\varepsilon_{\mathrm{ps}}$ & $\varepsilon_{\mathrm{us}}$ \\
\hline Steel beam & $1.28 \sigma_{\mathrm{ys}}$ & $10 \varepsilon_{\mathrm{ys}}$ & $30 \varepsilon_{\mathrm{ys}}$ \\
Rebar & $1.28 \sigma_{\mathrm{ys}}$ & $9 \varepsilon_{\mathrm{ys}}$ & $40 \varepsilon_{\mathrm{ys}}$ \\
Profiled sheeting & - & $20 \varepsilon_{\mathrm{ys}}$ & - \\
Shear stud & - & $25 \varepsilon_{\mathrm{ys}}$ & - \\
\hline
\end{tabular}


Table 4. Test results

\begin{tabular}{lllllll}
\hline Specimen & $\begin{array}{l}\text { Max. } \\
\text { load } \\
(\mathrm{kN})\end{array}$ & $\begin{array}{l}\text { Deflection at } \\
\text { max. load } \\
(\mathrm{mm})\end{array}$ & $\begin{array}{l}\text { Max. } \\
\text { moment } \\
(\mathrm{kNm})\end{array}$ & $\begin{array}{l}\text { Rotation at } \\
\text { max. moment } \\
(\mathrm{mrad})\end{array}$ & $\begin{array}{l}\text { Initial } \\
\text { stiffness } \\
(\mathrm{kNm} / \mathrm{mrad})\end{array}$ & $\begin{array}{l}\text { Failure } \\
\text { mode }\end{array}$ \\
\hline S1 & 352 & 52.7 & 594.88 & 28.89 & 99.74 & $1,2,3$ \\
S2 & 356 & 59.9 & 601.64 & 32.1 & 99.25 & $1,2,3$ \\
\hline
\end{tabular}

Failure mode: 1-cracking of concrete slab, 2- Bending of endplate, 3-Reinforcement bar fracture

Table 5. Comparison between test results and predictions

\begin{tabular}{lllllll}
\hline \multirow{2}{*}{ Specimen } & \multicolumn{3}{l}{ Moment resistance $(\mathrm{kNm})$} & \multicolumn{3}{l}{ Initial stiffness $(\mathrm{kNm} / \mathrm{mrad})$} \\
\cline { 2 - 7 } & Test & Predicted & Predicted/Test & Test & Predicted & Predicted/Test \\
\hline S1 & 594.88 & 588.5 & 0.98 & 99.74 & 95.93 & 0.96 \\
S2 & 601.64 & 616.9 & 1.02 & 99.25 & 100.02 & 1.01 \\
\hline
\end{tabular}

Table 6. Parameters selected for parametric studies

\begin{tabular}{lll}
\hline No. & Parameter & Value \\
\hline 1 & Endplate thickness $(\mathrm{mm})$ & $8,10,12,16,20$ \\
2 & Equal angle thickness $(\mathrm{mm})$ & $8,10,12,16,19$ \\
3 & Reinforcement ratio $(\%)$ & $\mathrm{N} 12, \mathrm{~N} 16, \mathrm{~N} 24, \mathrm{~N} 28$ \\
4 & Shear connection ratio $(\%)$ & $35,50,100,140$ \\
5 & Slab depth $(\mathrm{mm})$ & $120,150,200,250$ \\
\hline
\end{tabular}




\section{Figure Captions}

Fig. 1. Typical layout of a flush endplate composite connection.........................................26

Fig. 2. (a) Ajax one side fastener [1], (b) Ajax installation tool and (c) Installation of Ajax..26

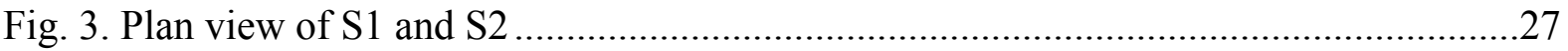

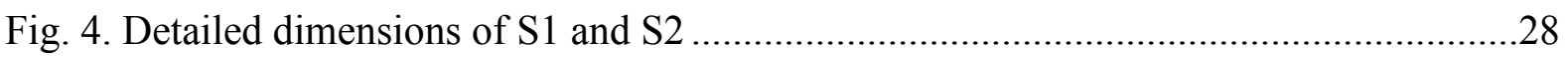

Fig. 5. Proposed composite connection with the addition of equal angle sections .................28

Fig. 6. Laying of reinforcement mesh and profiled sheeting .............................................28

Fig. 7. Stress-strain relationship of structural steel materials ............................................29

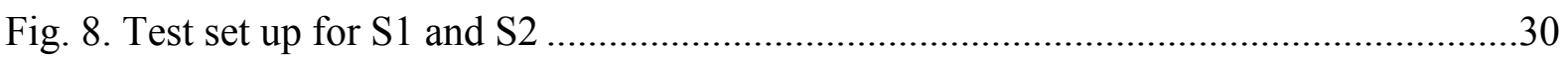

Fig. 9.Installation of strain gauges on reinforcement embedded in concrete slab ..................30

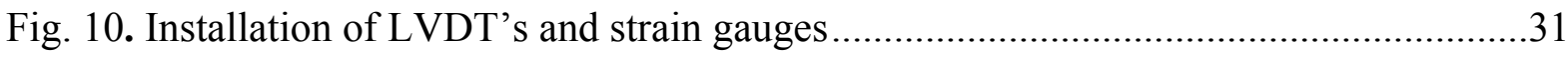

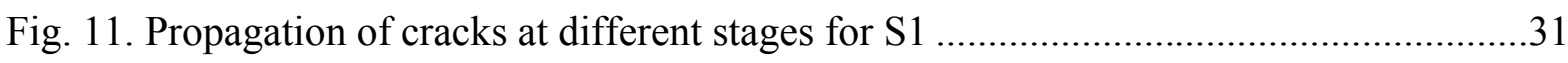

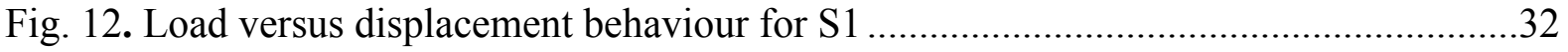

Fig. 13. Loading protocol planned for S2 according to AISC ...........................................32

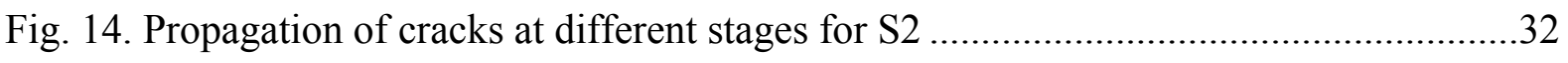

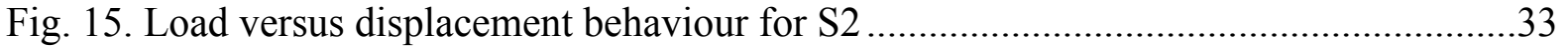

Fig. 16. Cracking of concrete slab: experiment versus FE model ........................................33

Fig. 17. Bending of top of flush endplate: experiment versus FE model...............................34

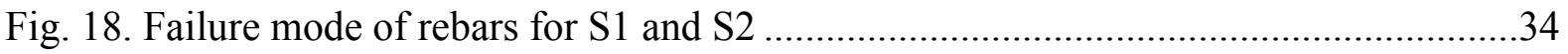

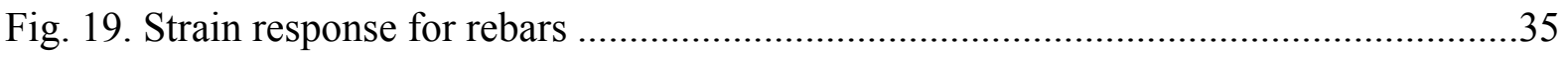

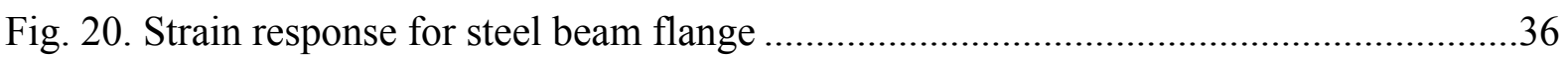

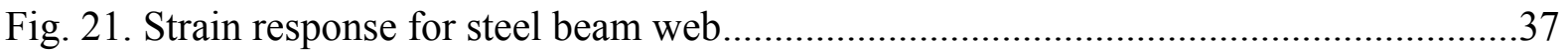

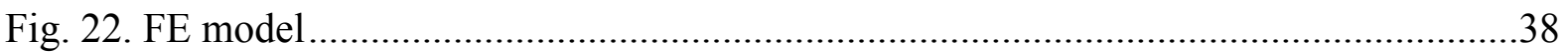

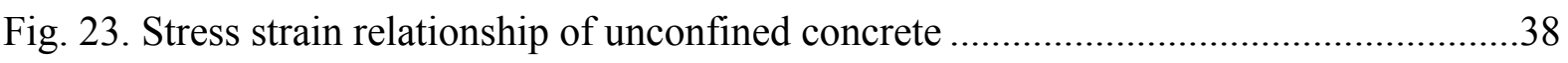

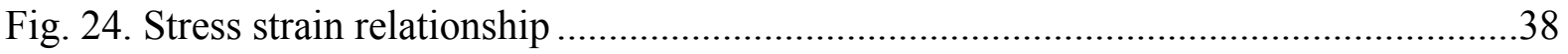

Fig. 25. Comparison of load displacement behaviour of beam-to-column flush endplate

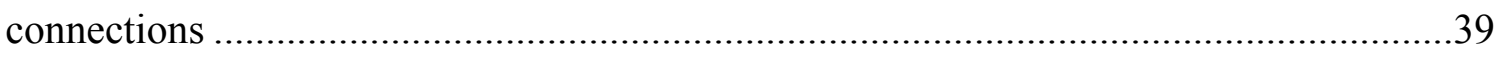

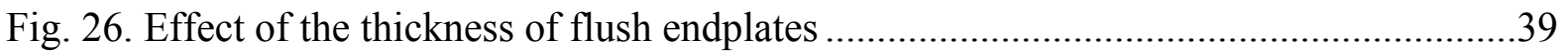

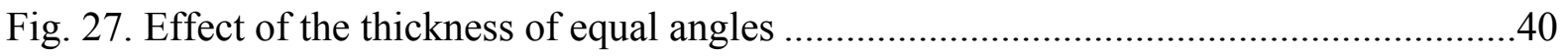

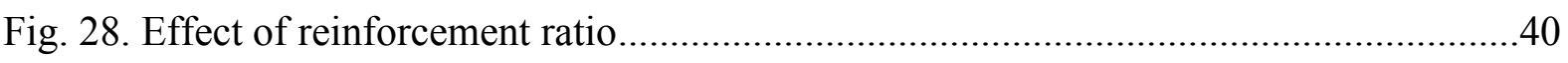

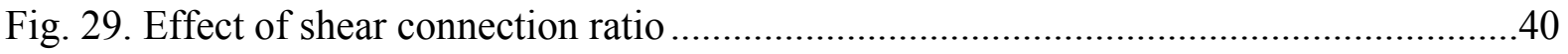

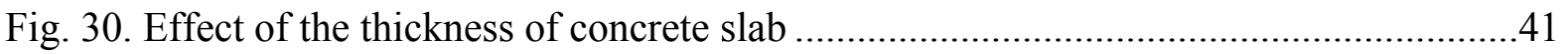




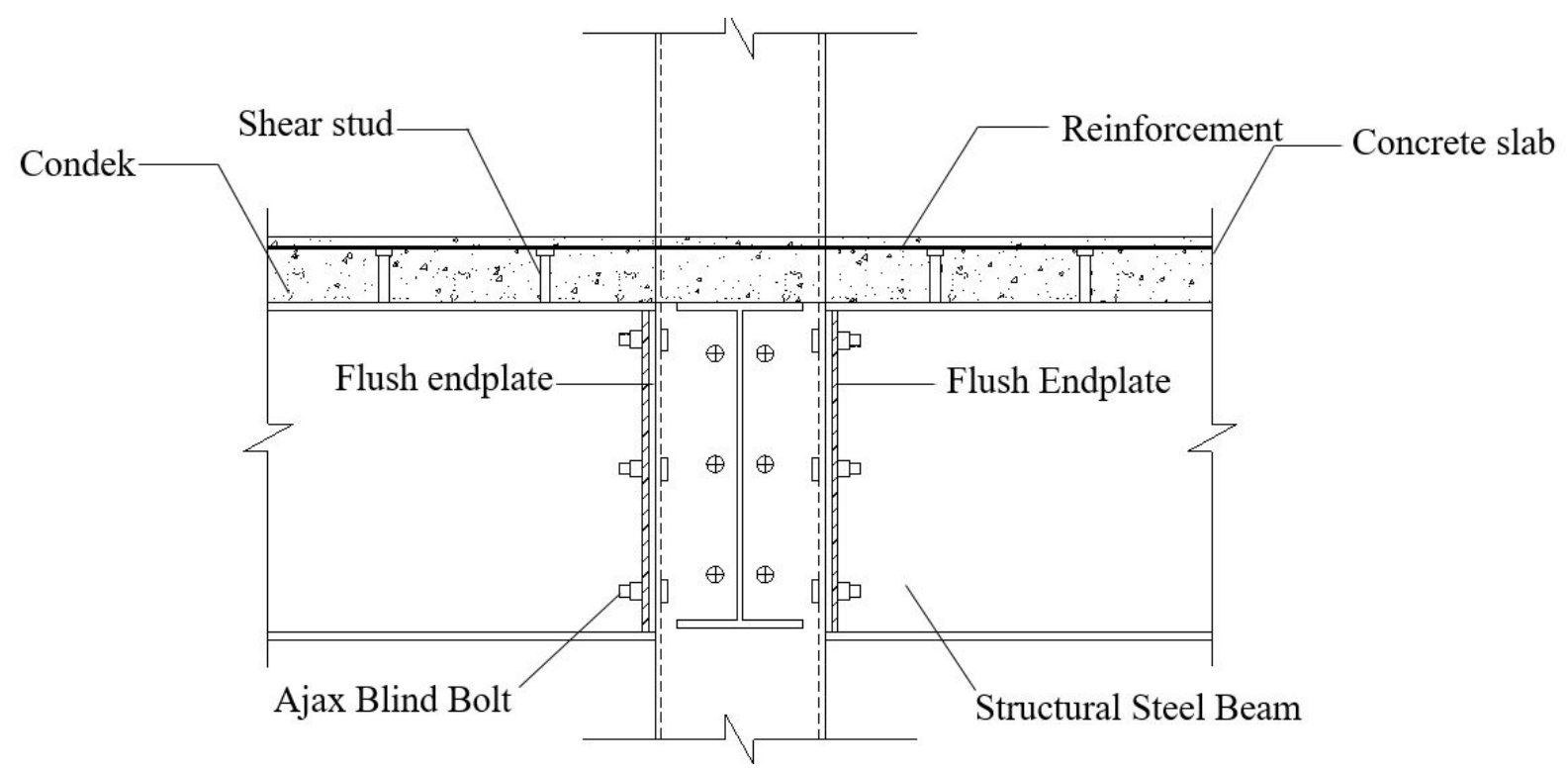

Fig. 1. Typical layout of a flush endplate composite connection

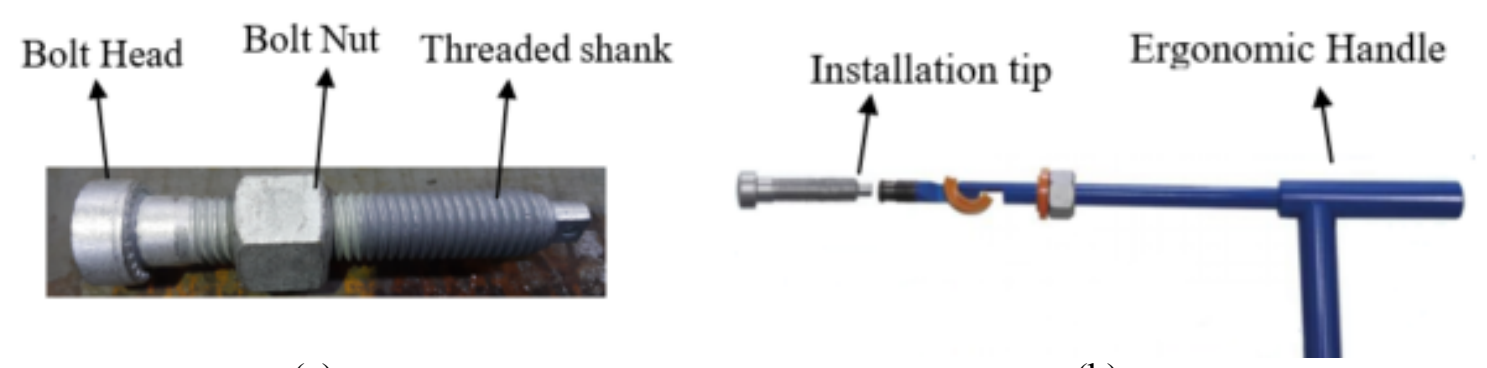

(a)

(b)

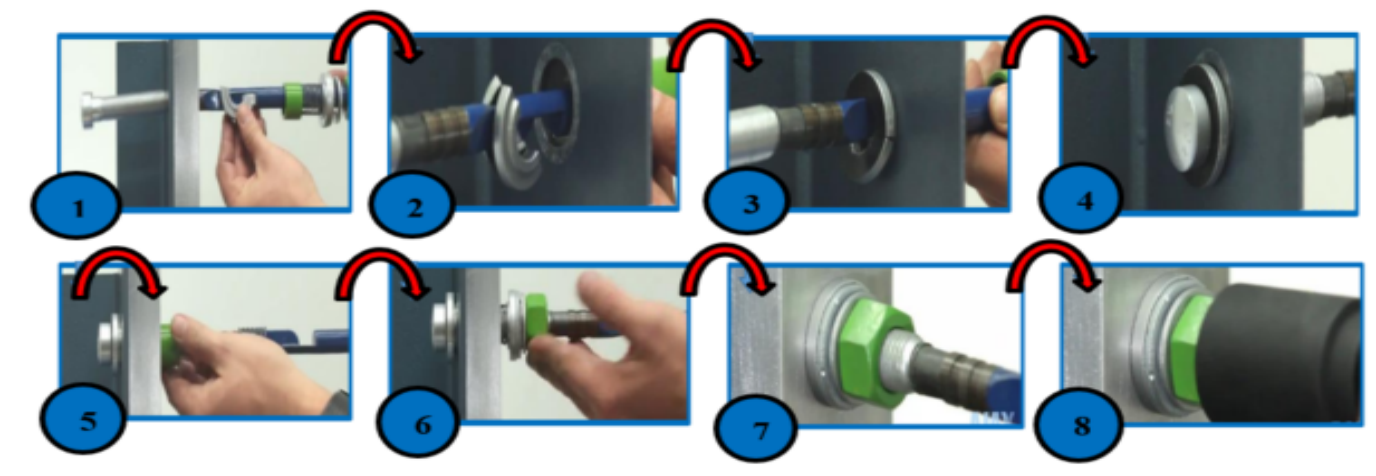

(c)

Fig. 2. (a) Ajax one side fastener [1], (b) Ajax installation tool and (c) Installation of Ajax 


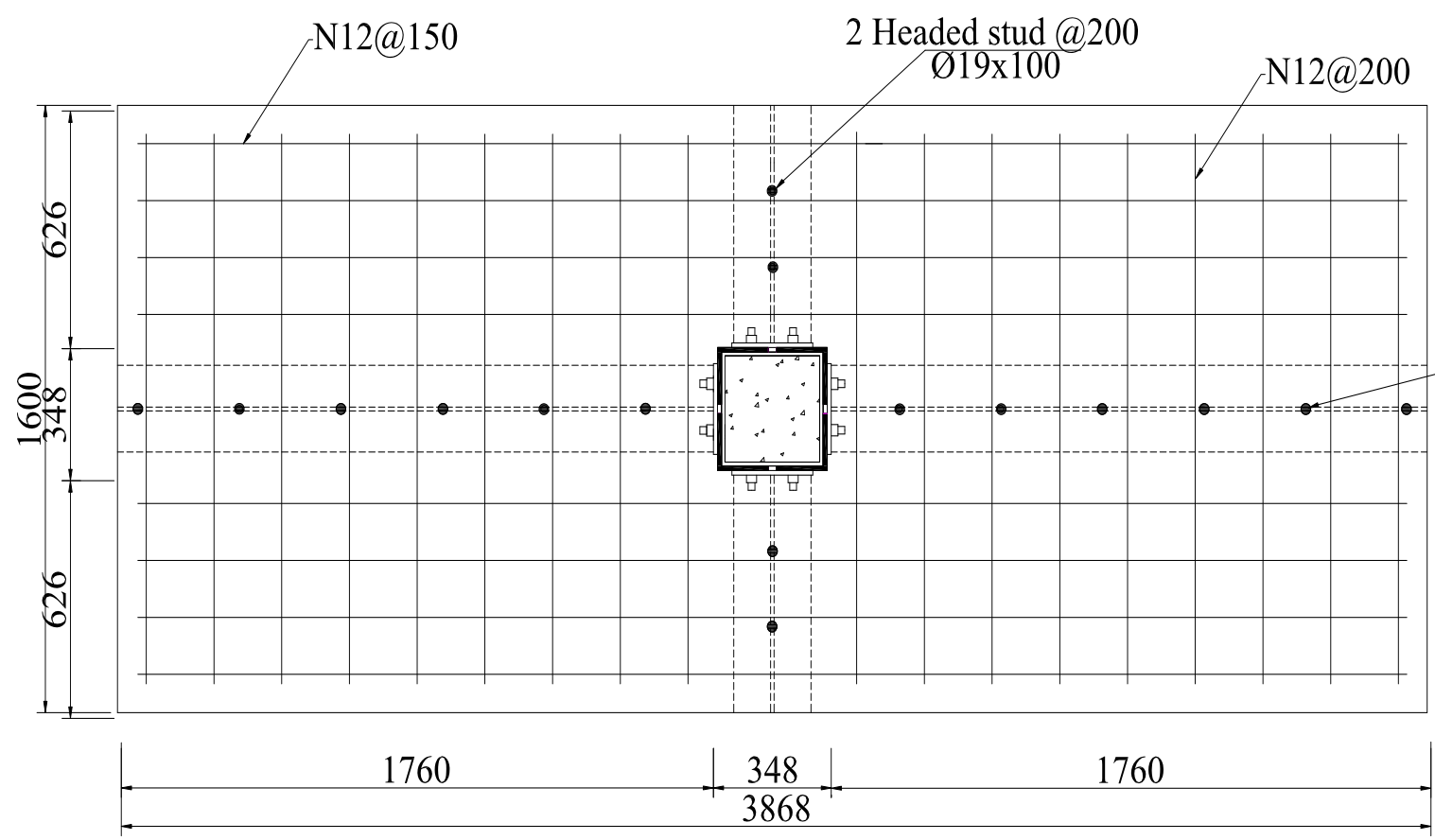

Headed stud@300 $\varnothing 19 \times 100$

Fig. 3. Plan view of S1 and S2
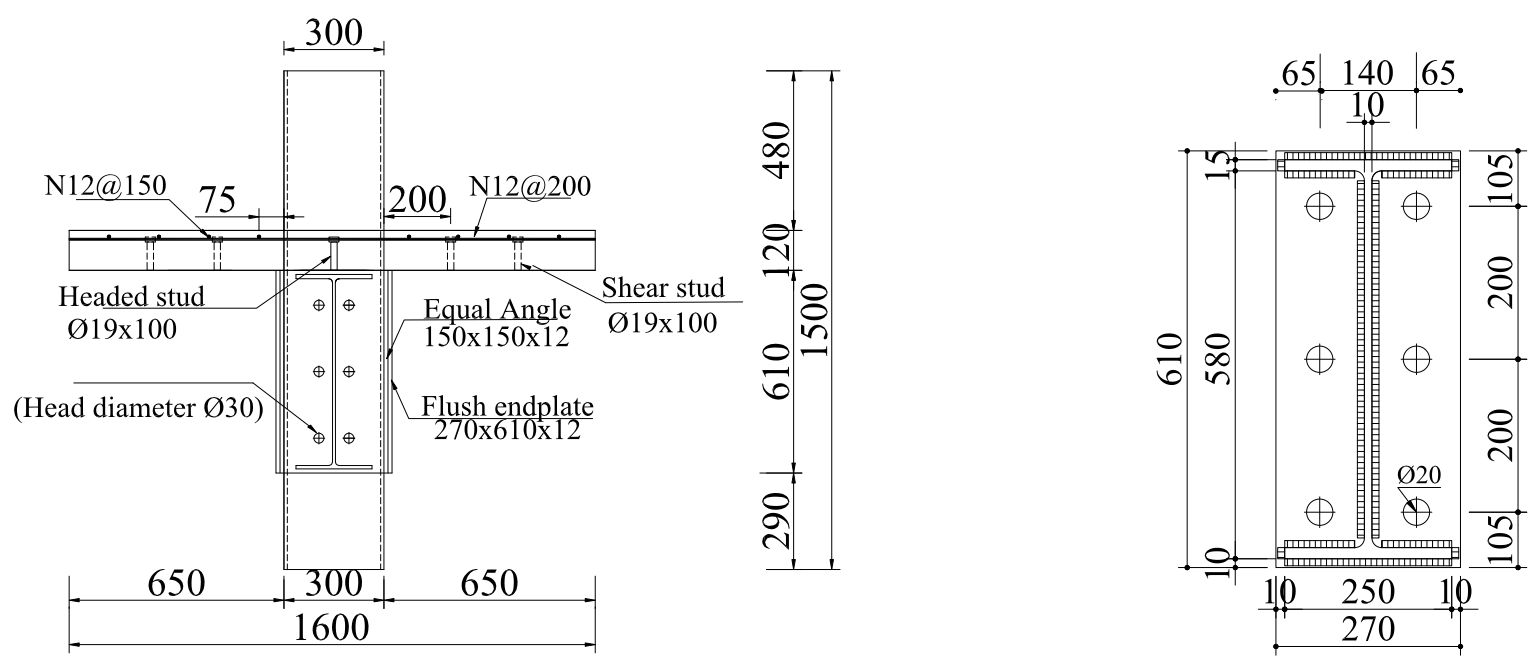


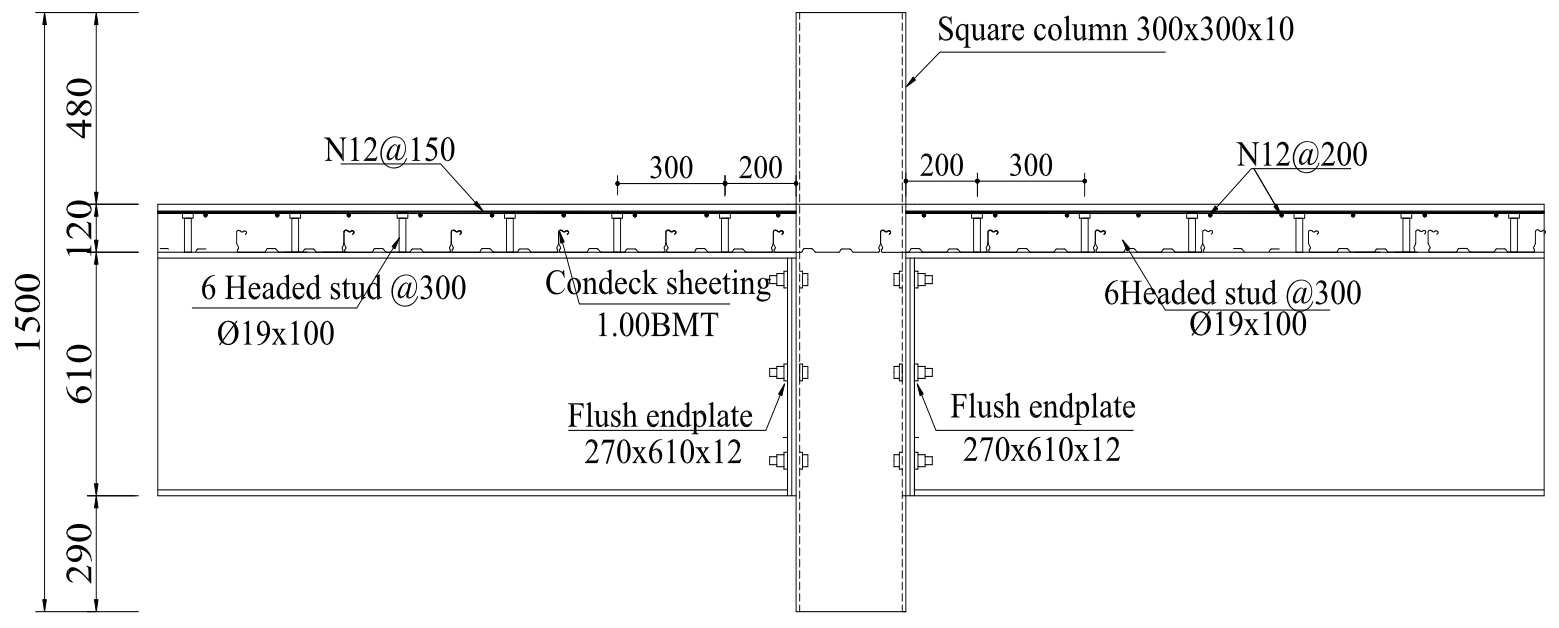

Fig. 4. Detailed dimensions of S1 and S2

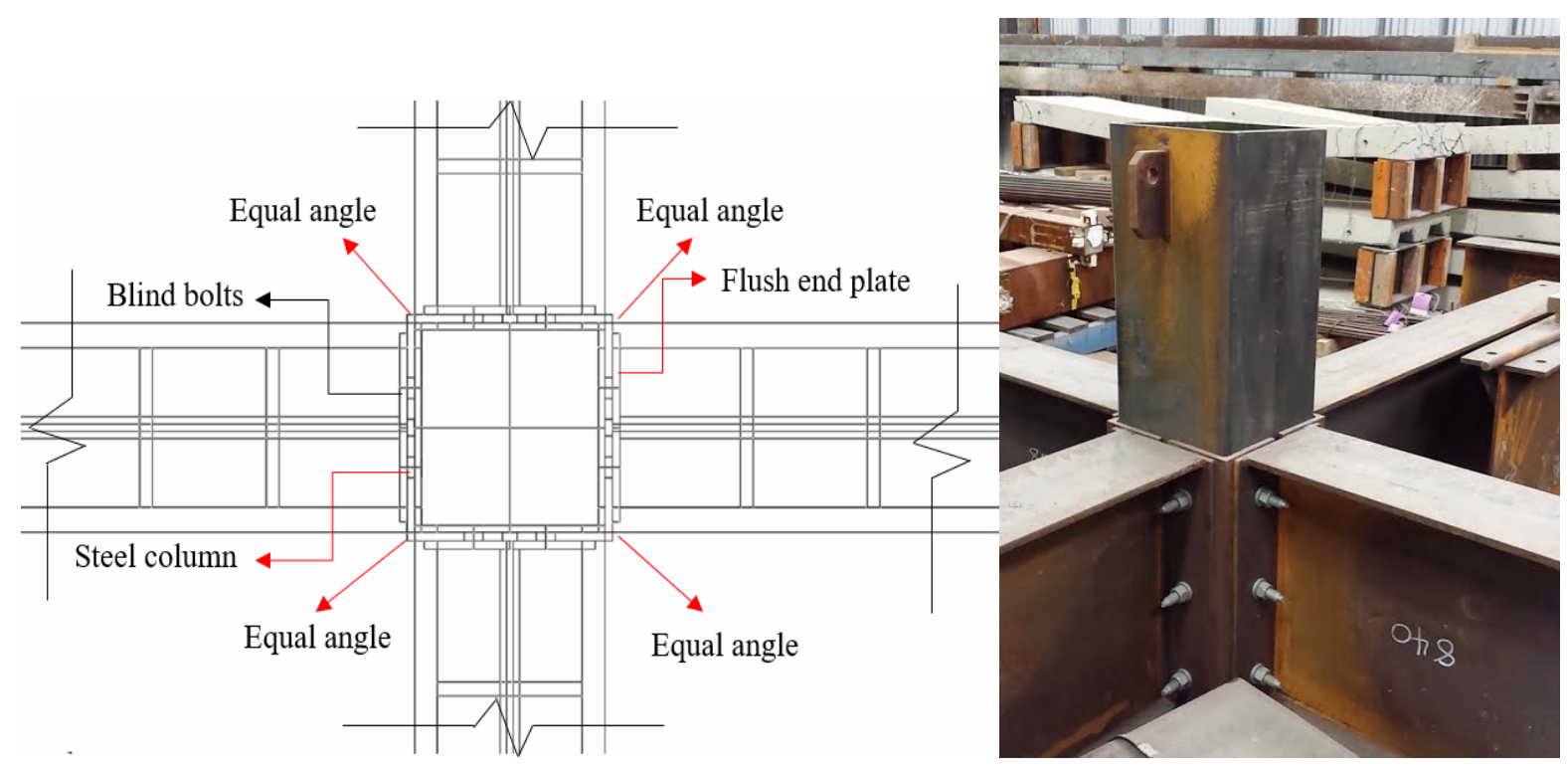

Fig. 5. Proposed composite connection with the addition of equal angle sections

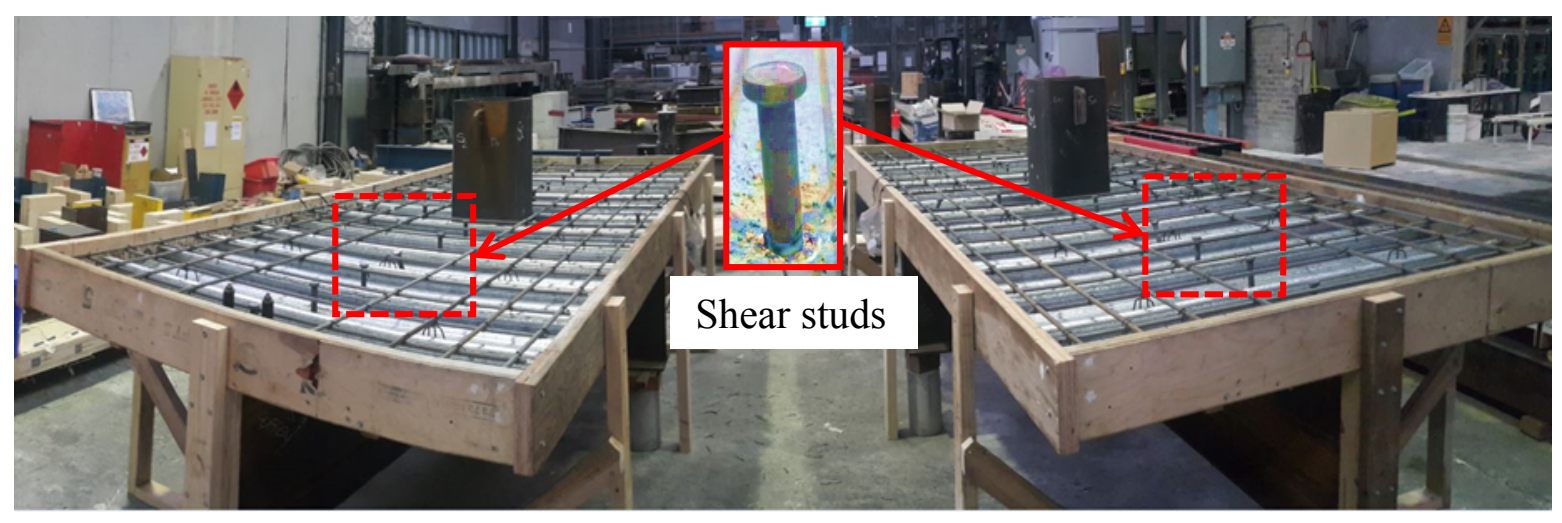

Fig. 6. Laying of reinforcement mesh and profiled sheeting 


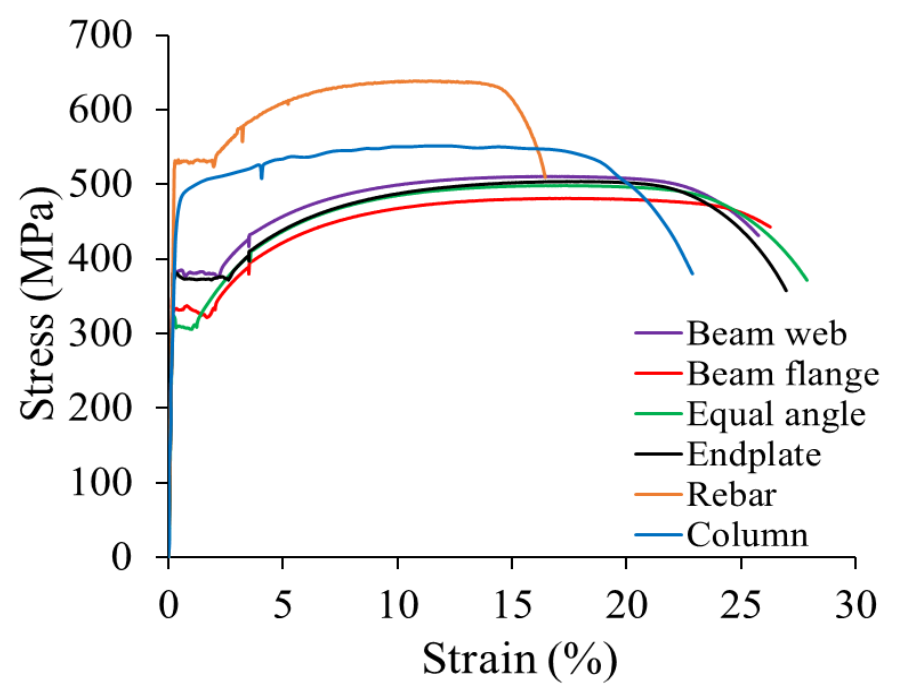

(a) Rebar, equal angle, beam web, beam flange and endplate

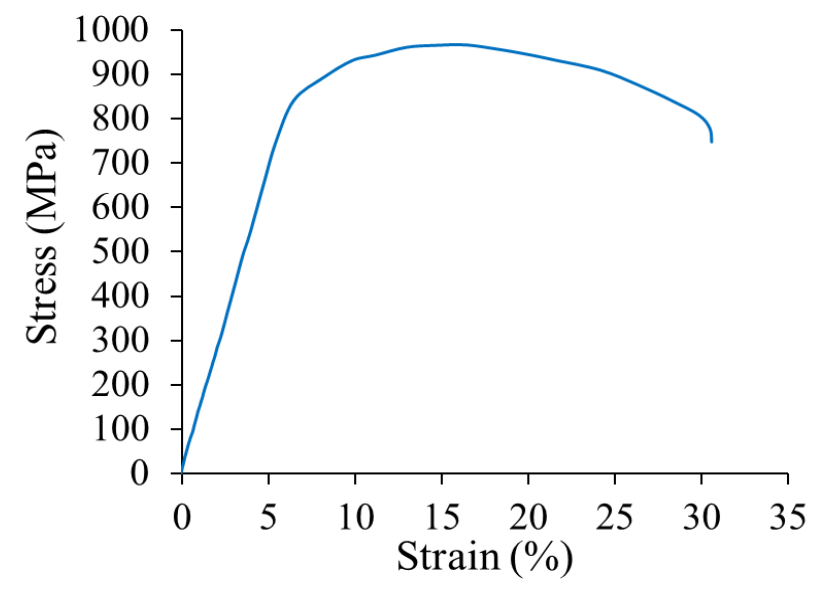

(b) Bolt

Fig. 7. Stress-strain relationship of structural steel materials 


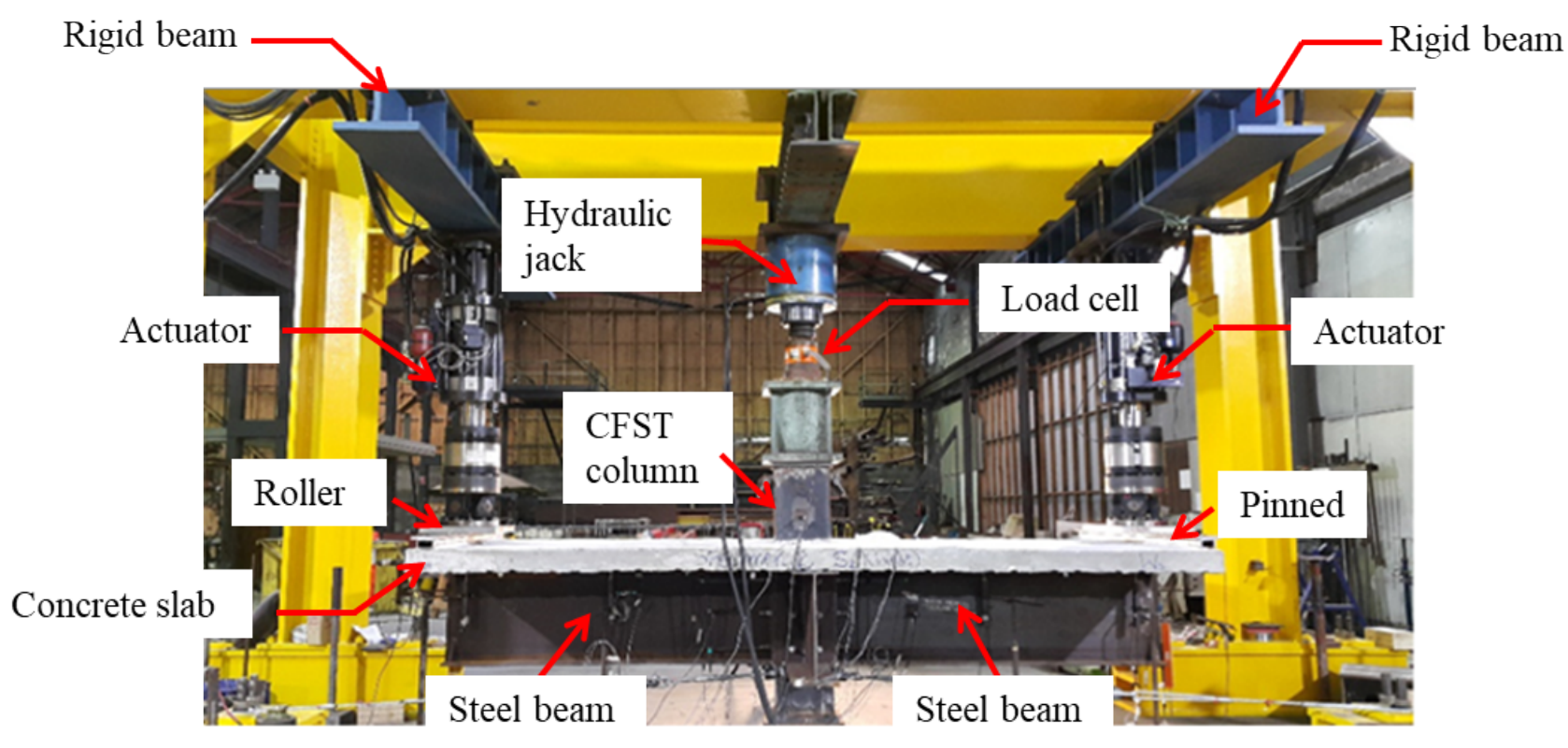

Fig. 8. Test set up for S1 and S2
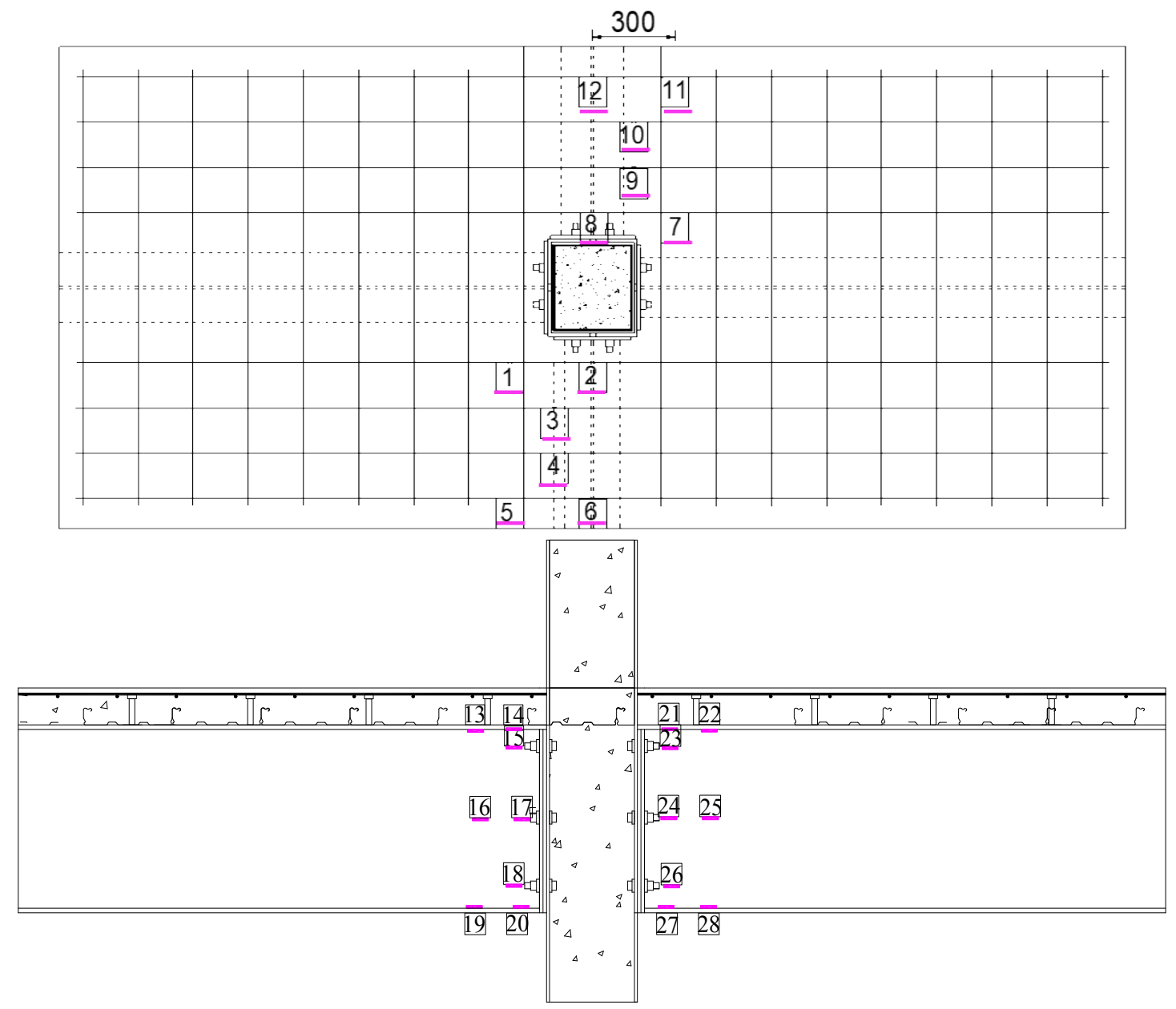

Fig. 9.Installation of strain gauges on reinforcement and steel beam 

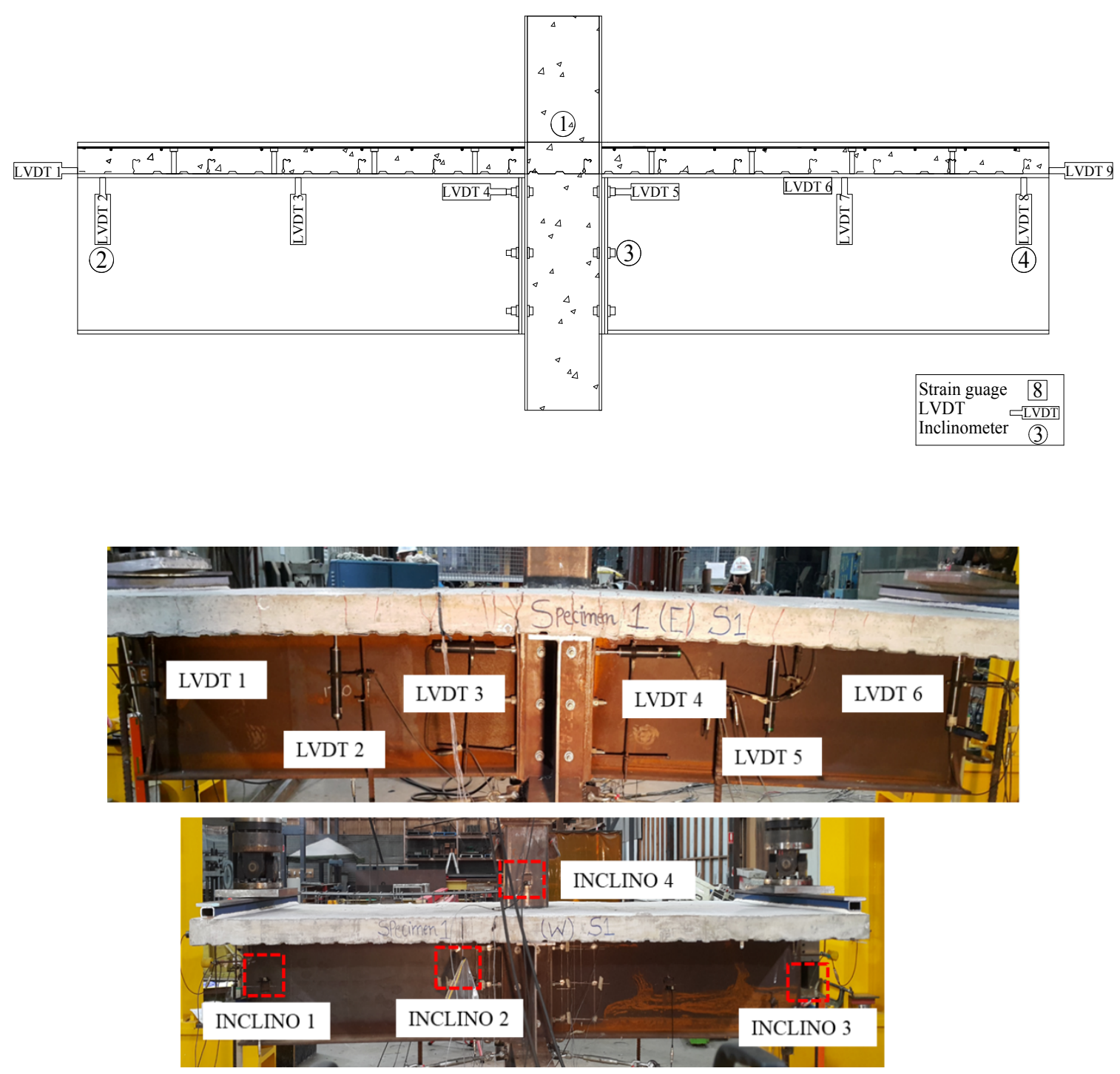

Fig. 10. Installation of LVDT's and inclinometers

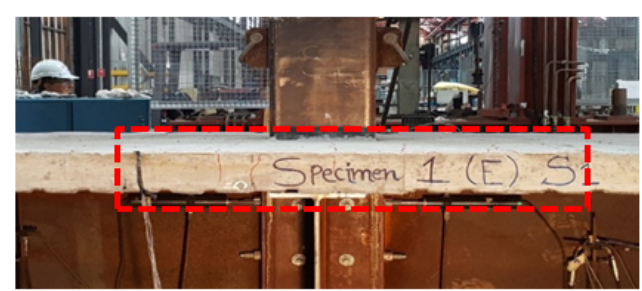

(a)

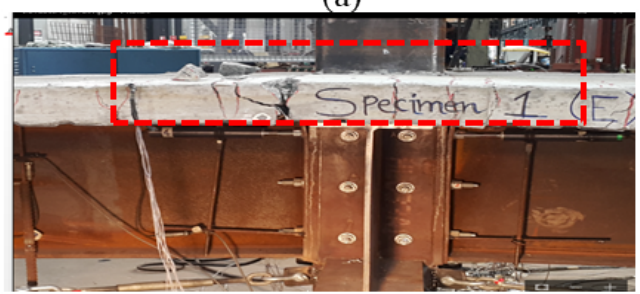

(c)

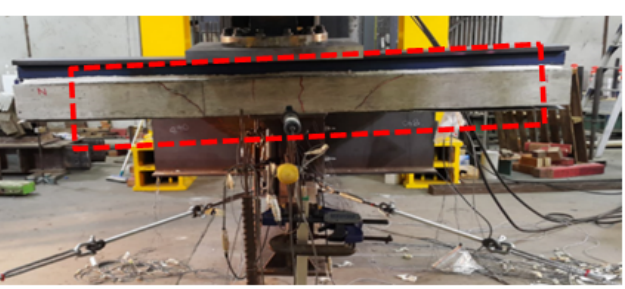

(b)

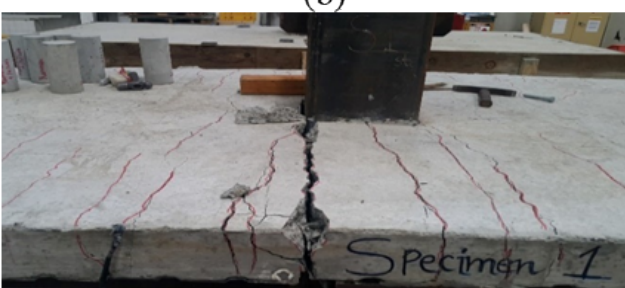

(d)

Fig. 11. Propagation of cracks at different stages for S1 


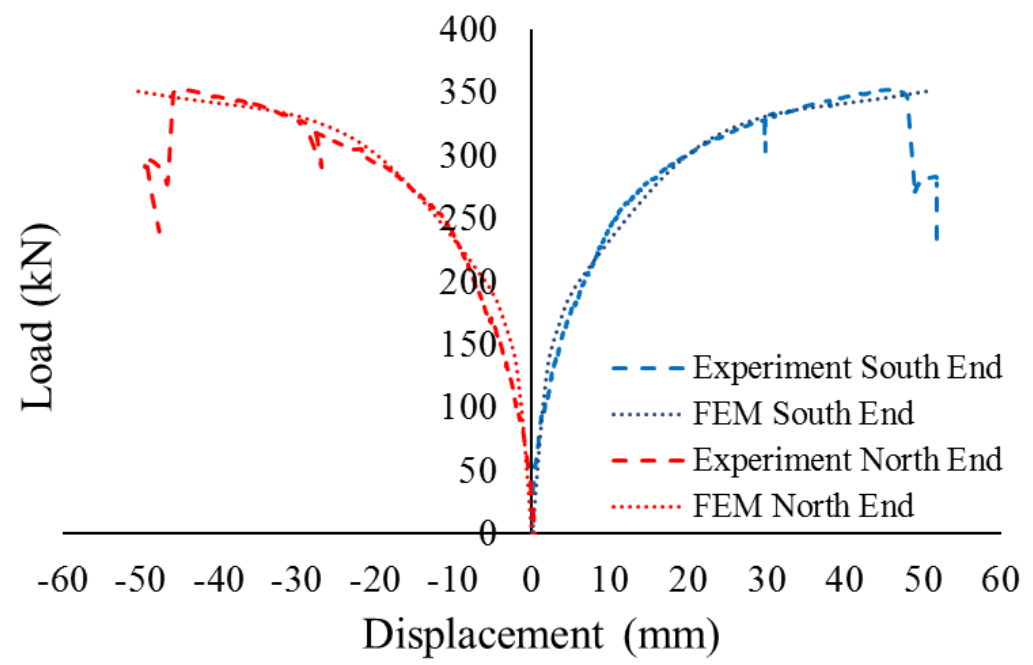

Fig. 12. Load versus displacement behaviour for S1

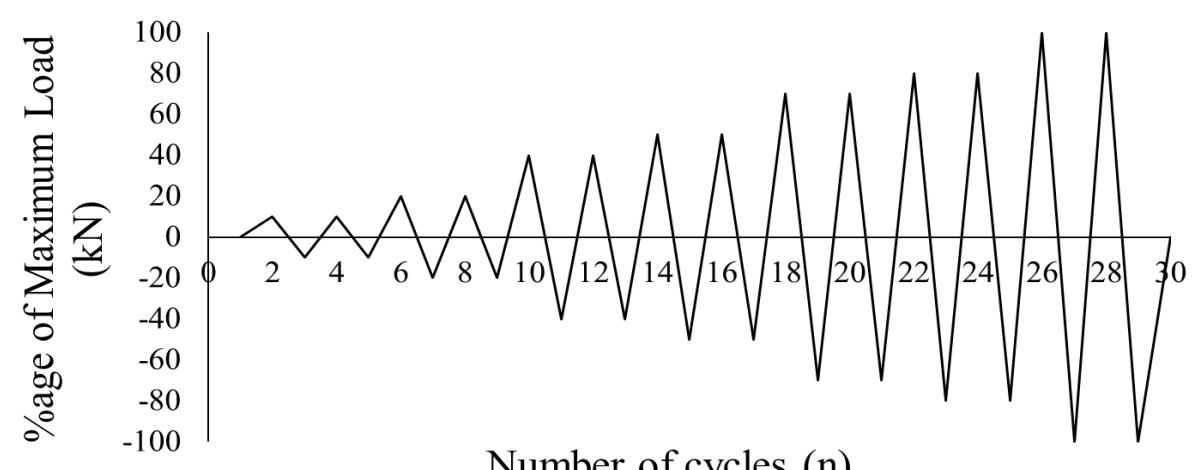

Number of cycles (n)

Fig. 13. Loading protocol planned for S2 according to AISC

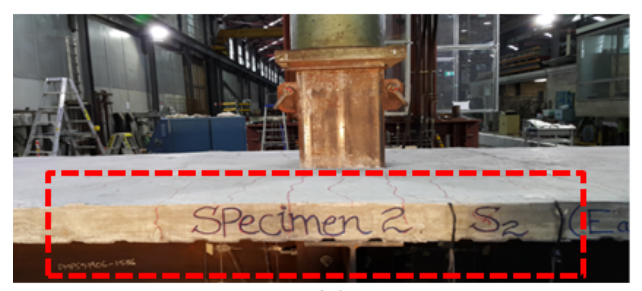

(a)

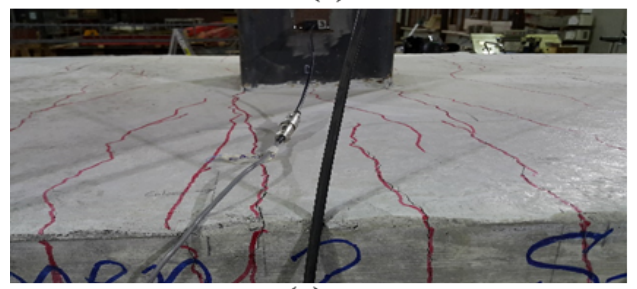

(c)

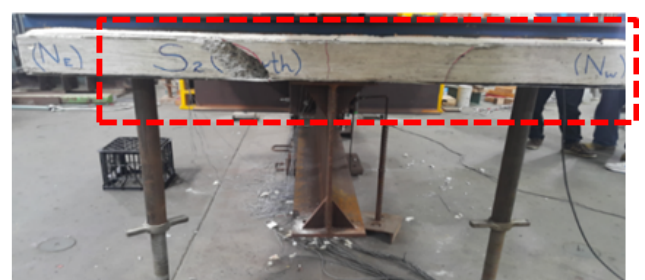

(b)

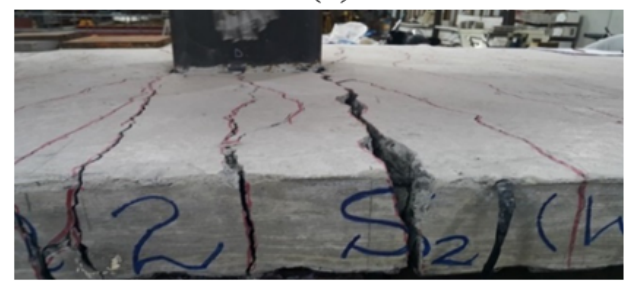

(d)

Fig. 14. Propagation of cracks at different stages for S2 


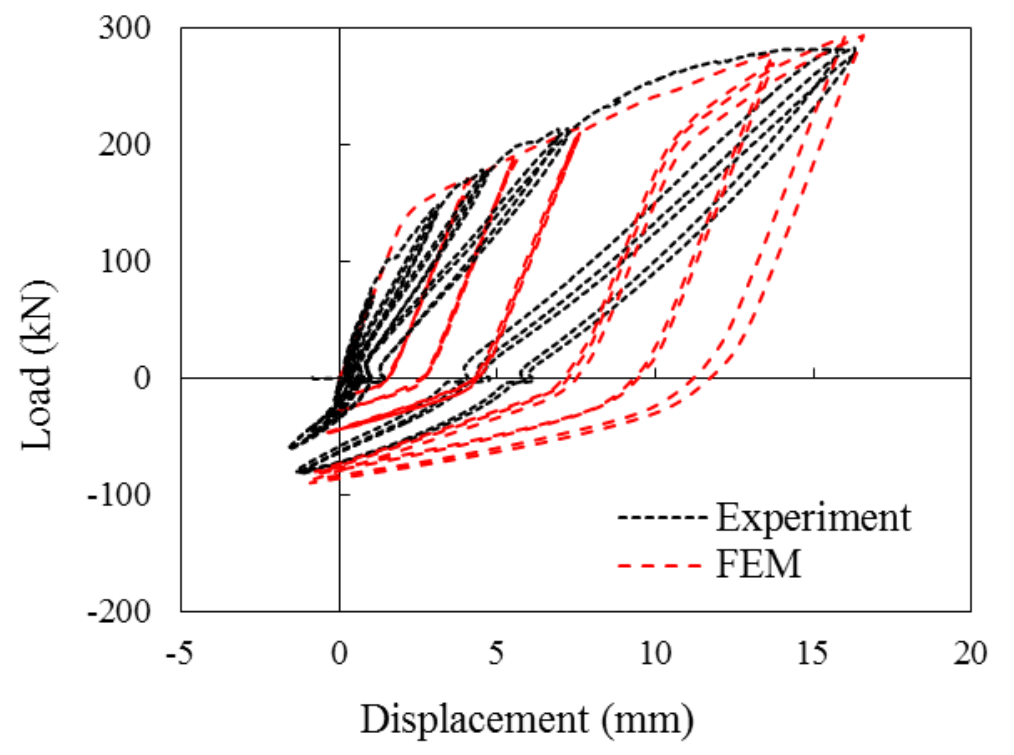

Fig. 15. Load versus displacement behaviour for S2

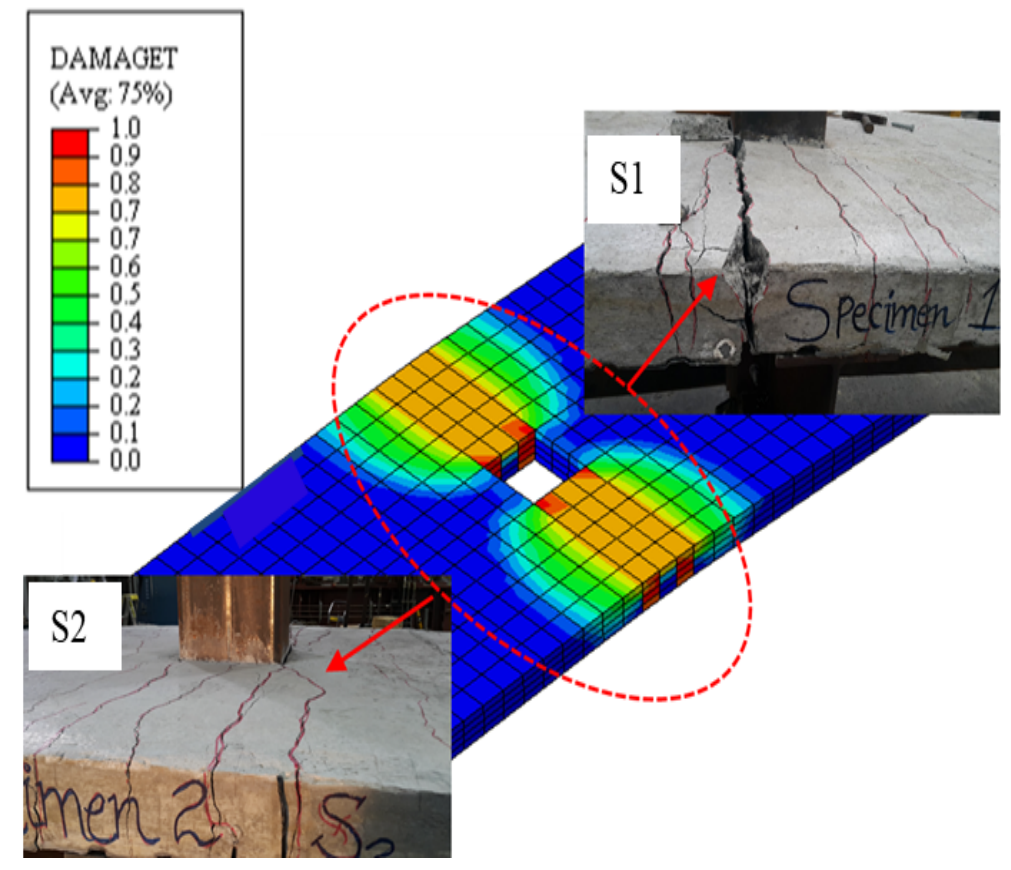

Fig. 16. Cracking of concrete slab: experiment versus FE model 


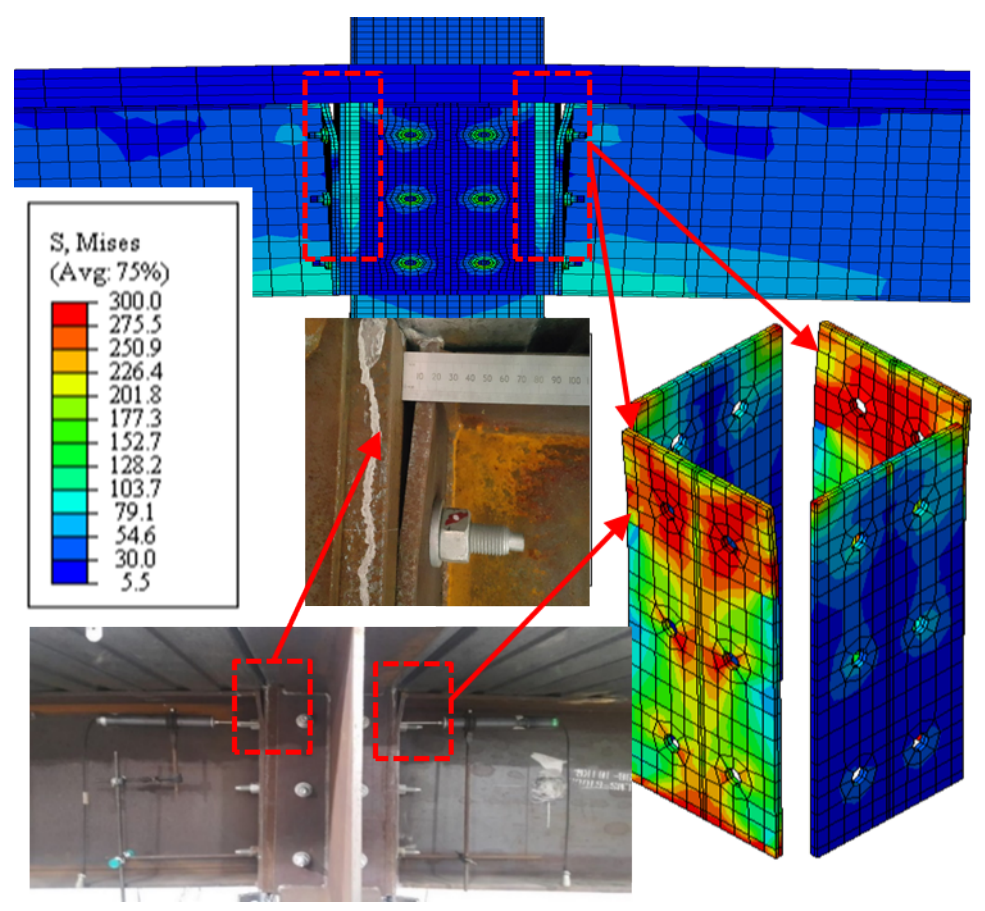

Fig. 17. Bending of top of flush endplate: experiment versus FE model
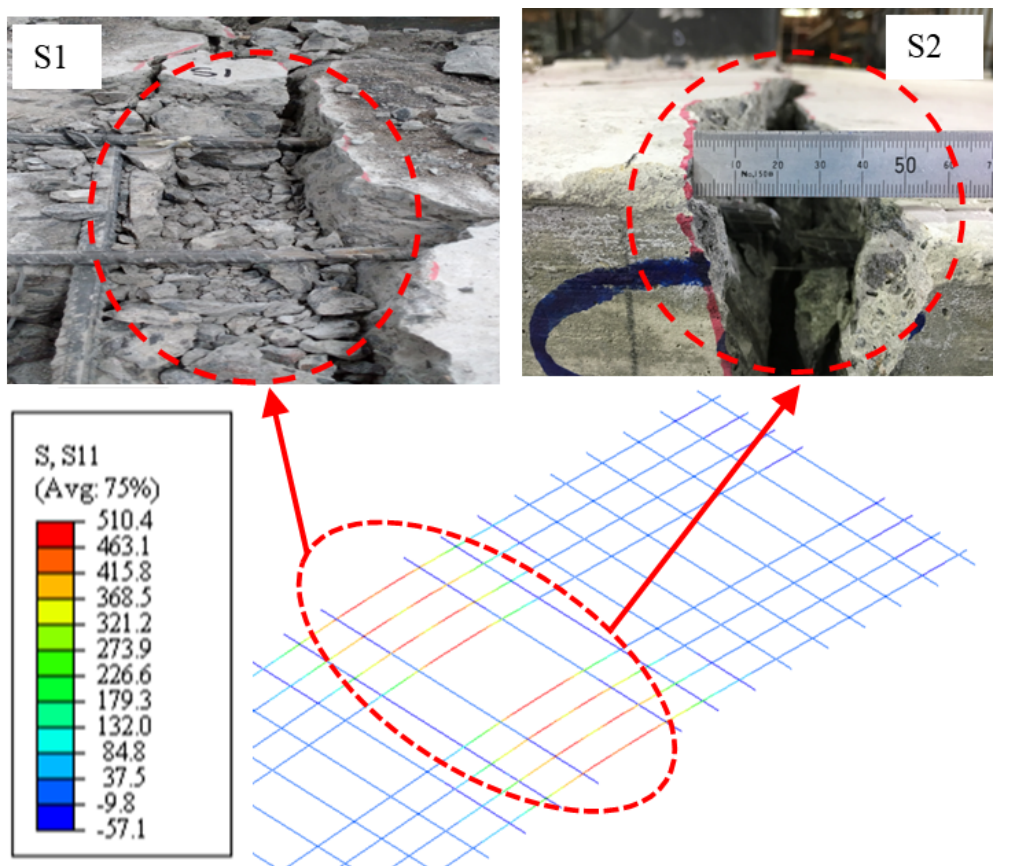

Fig. 18. Failure mode of rebars for S1 and S2 


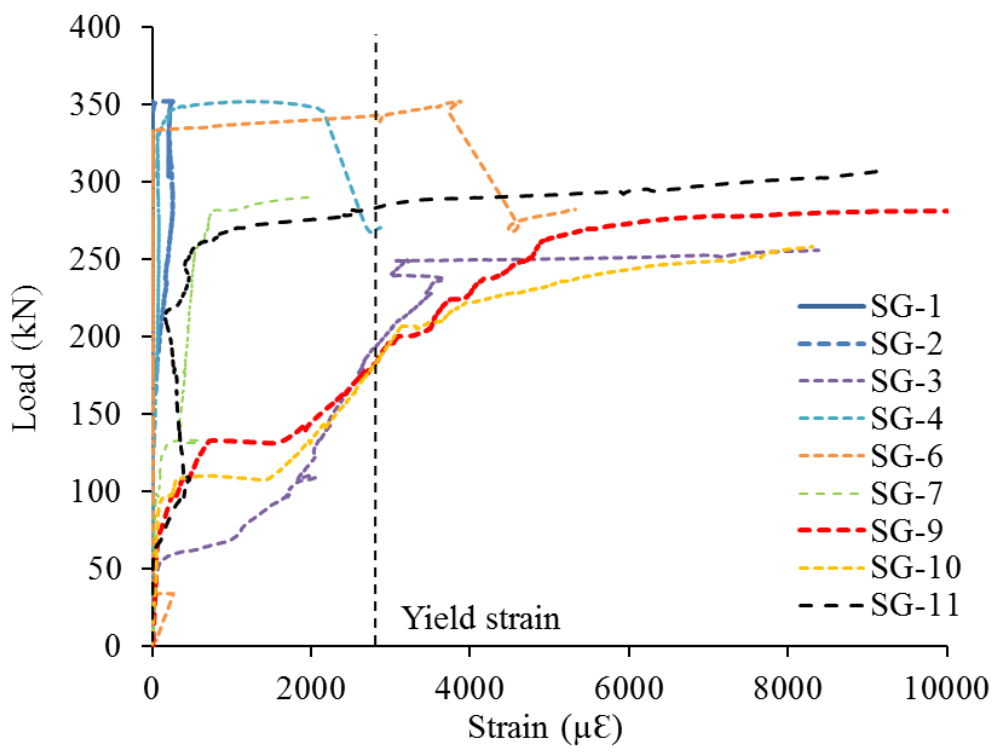

(a) S1

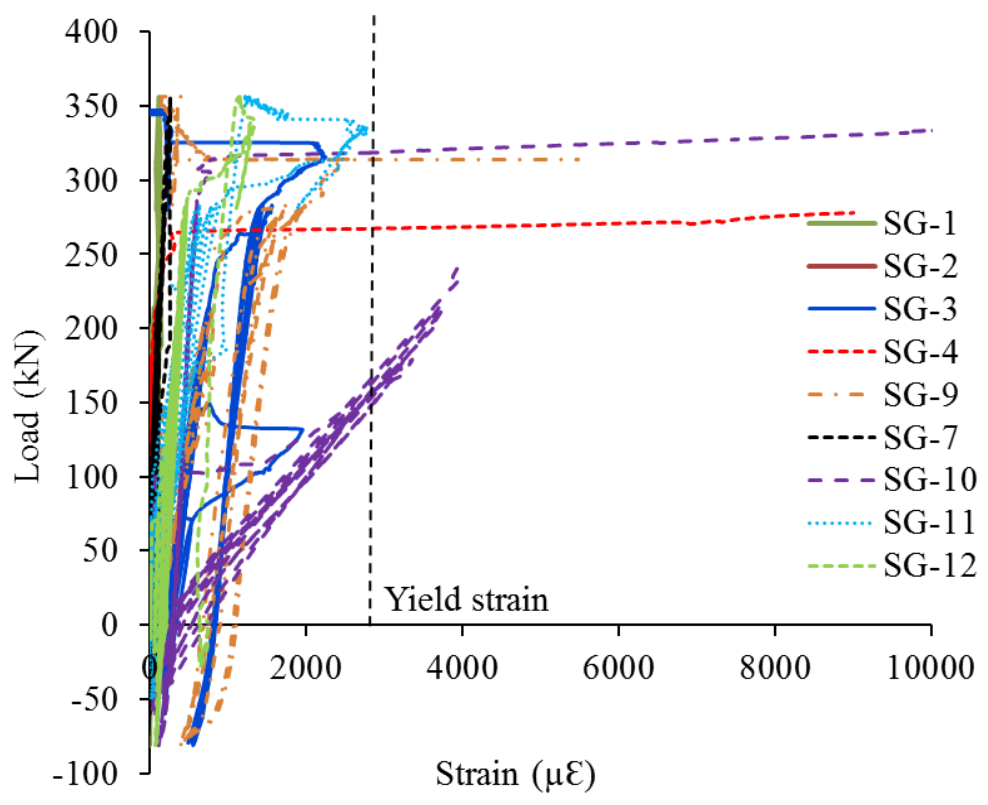

b) $\mathrm{S} 2$

Fig. 19. Strain response for rebars 


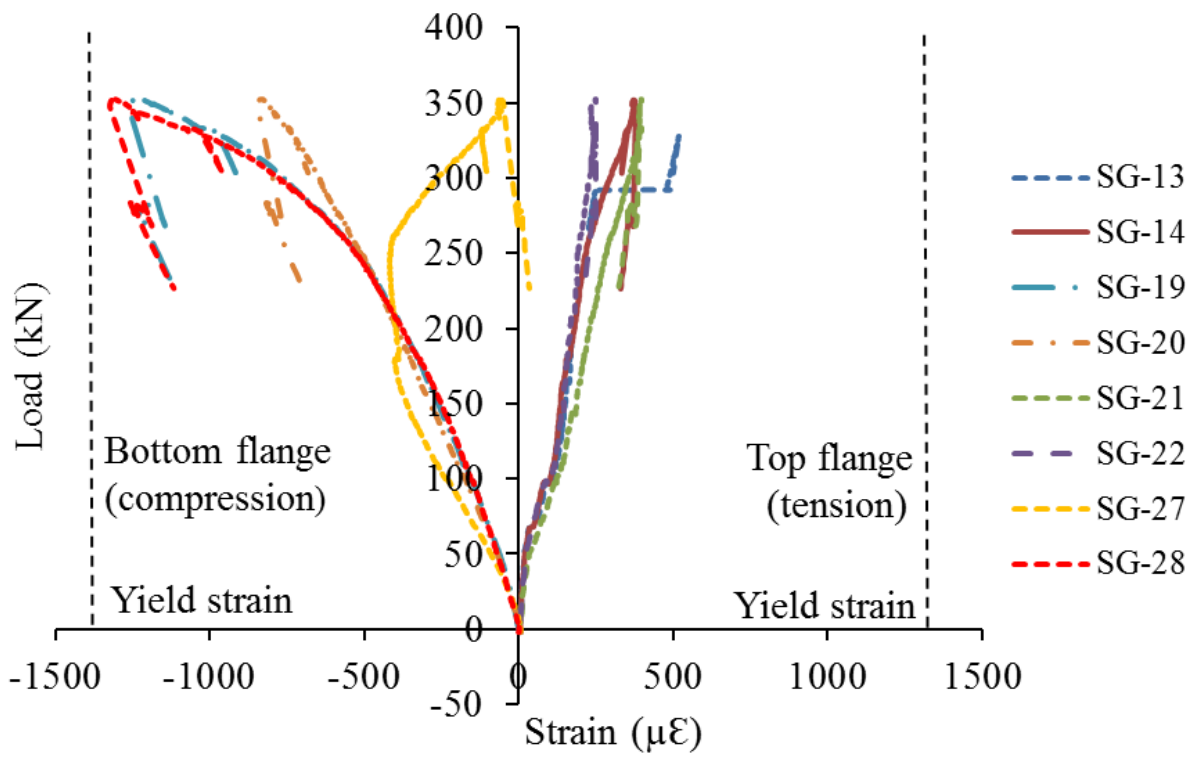

(a) $\mathrm{S} 1$

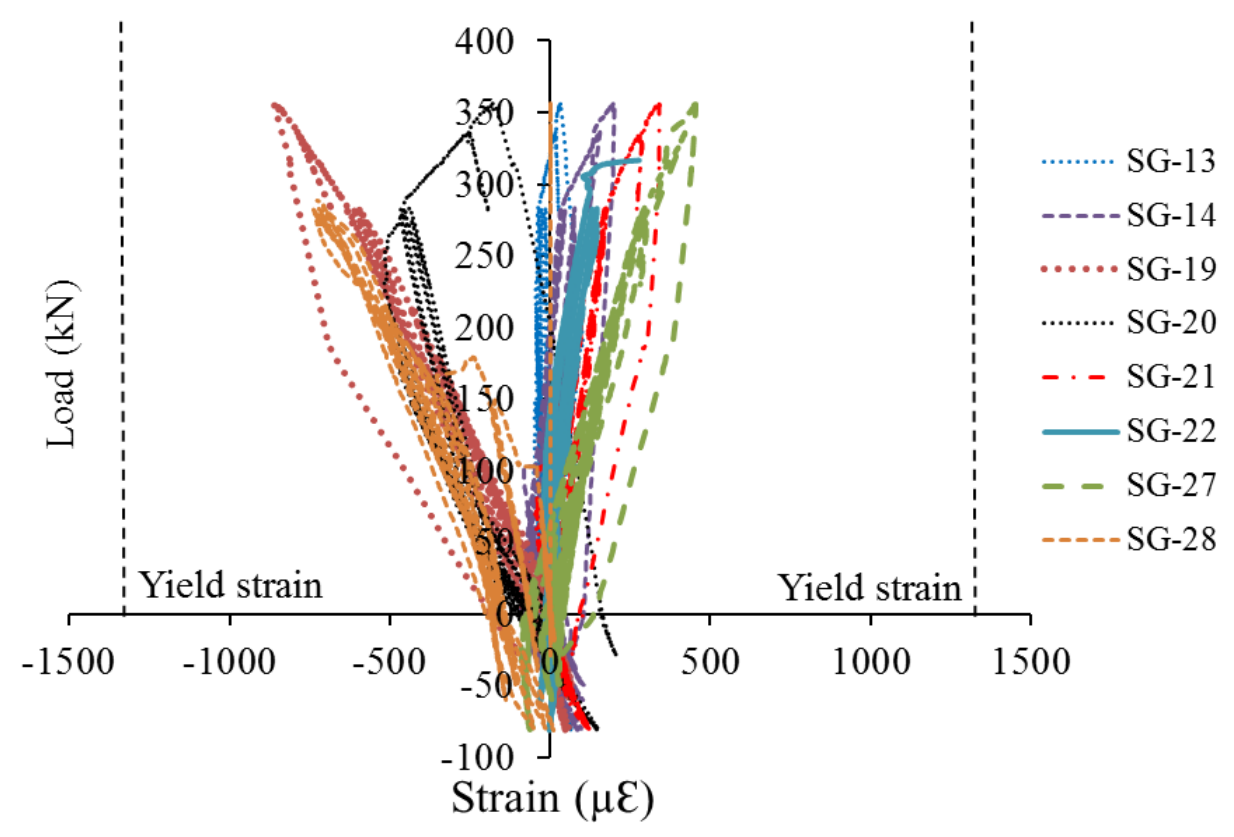

(b) S2

Fig. 20. Strain response for steel beam flange 


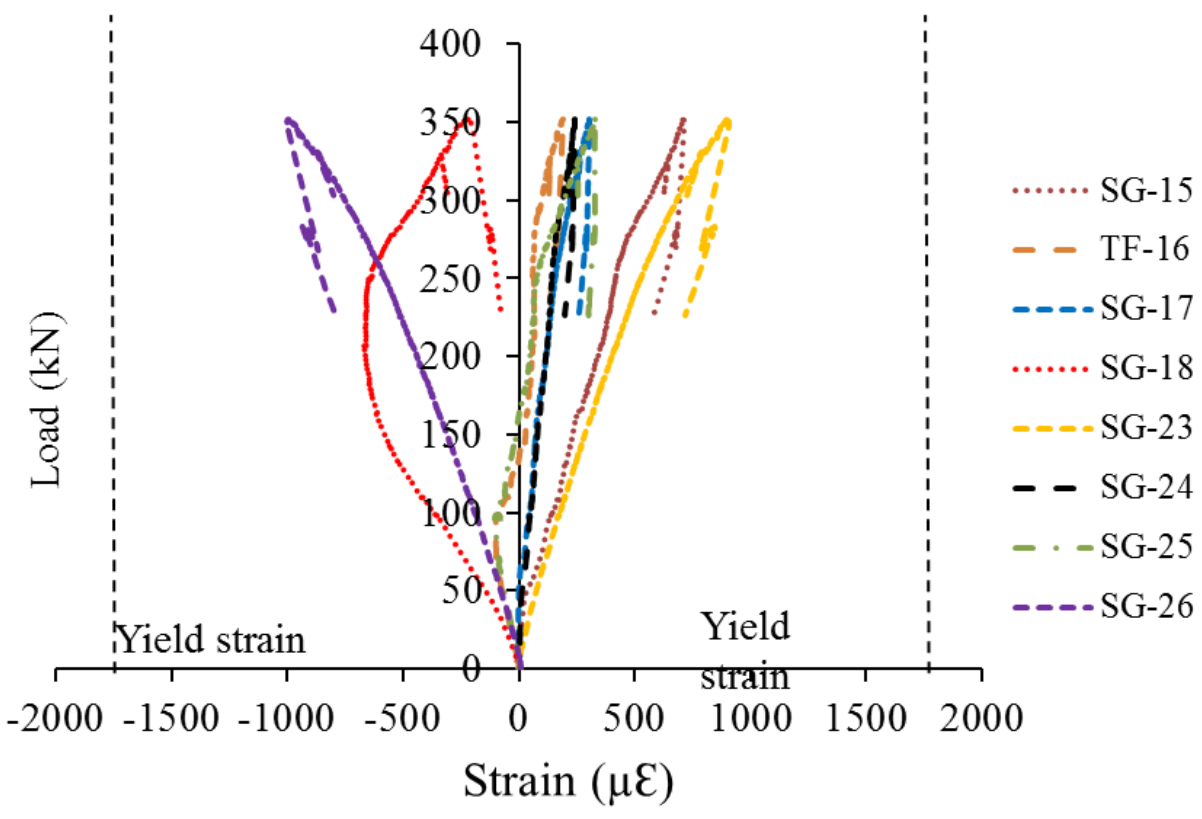

(a) S1

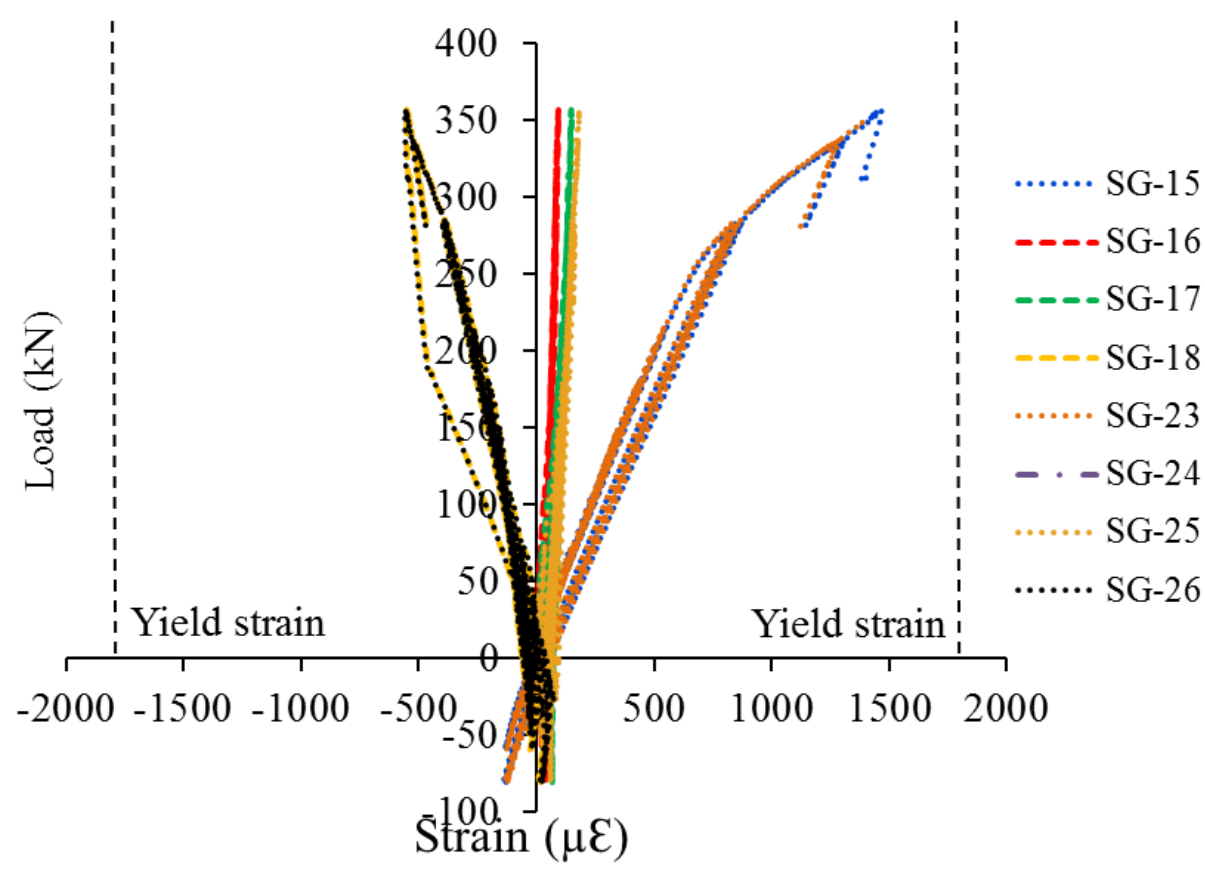

(b) S2

Fig. 21. Strain response for steel beam web 


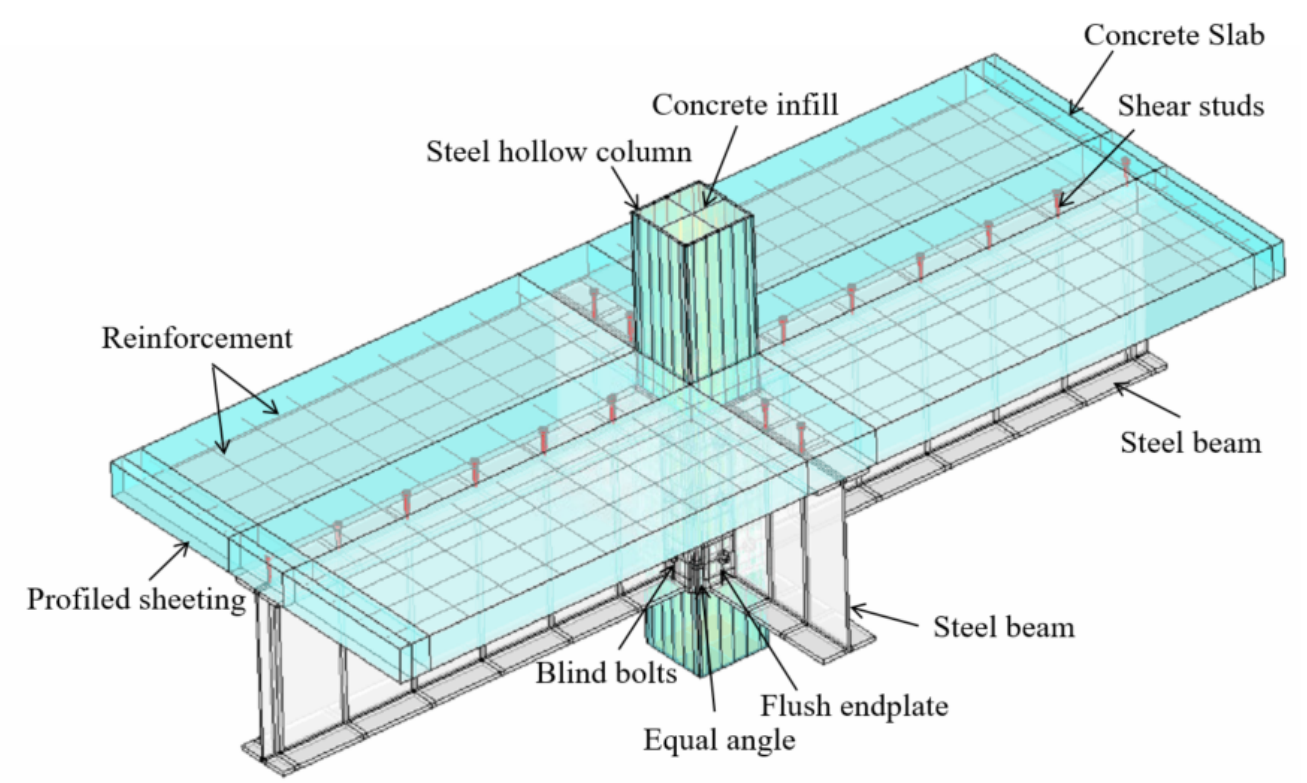

Fig. 22. FE model

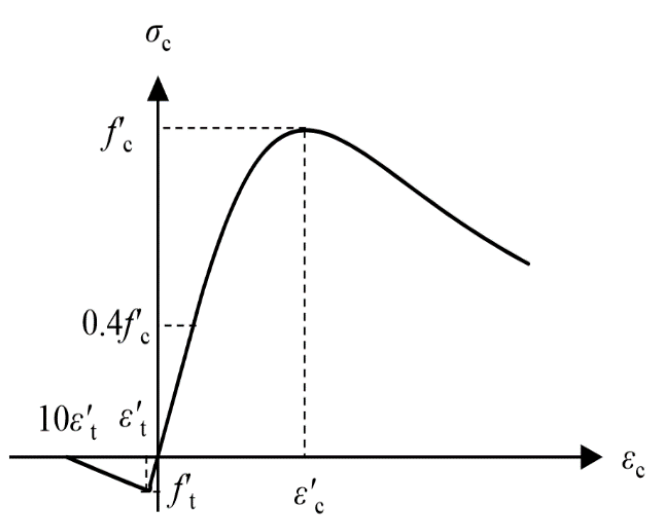

(a) Static loading

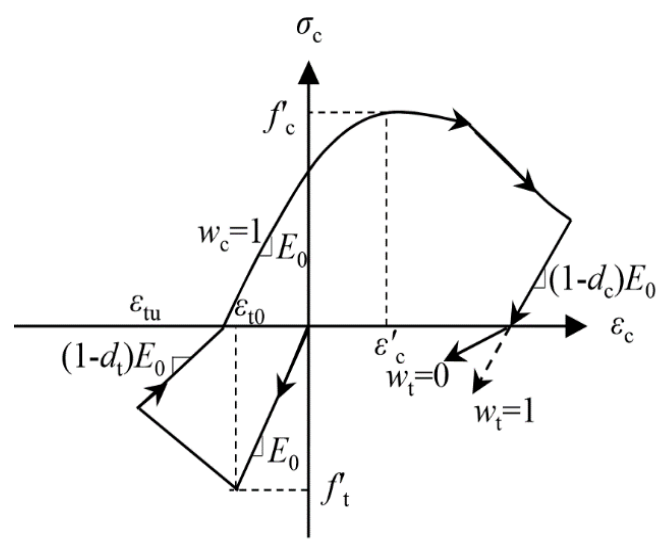

(b) Cyclic loading

Fig. 23. Stress strain relationship of unconfined concrete

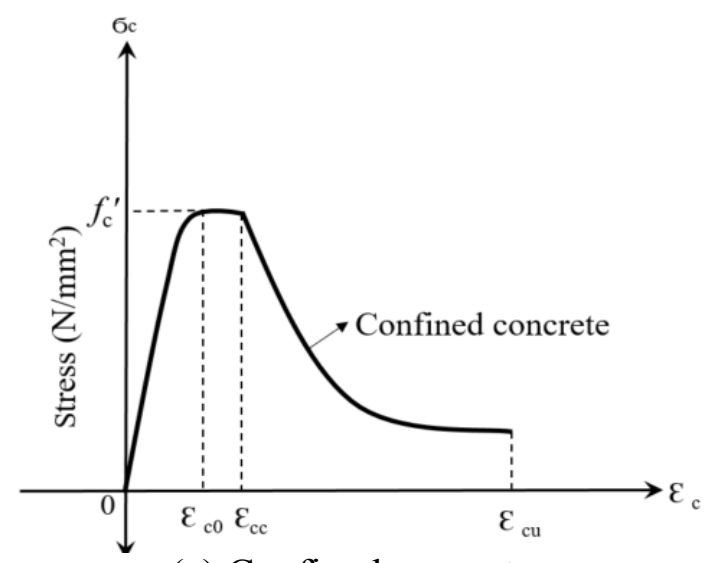

(a) Confined concrete

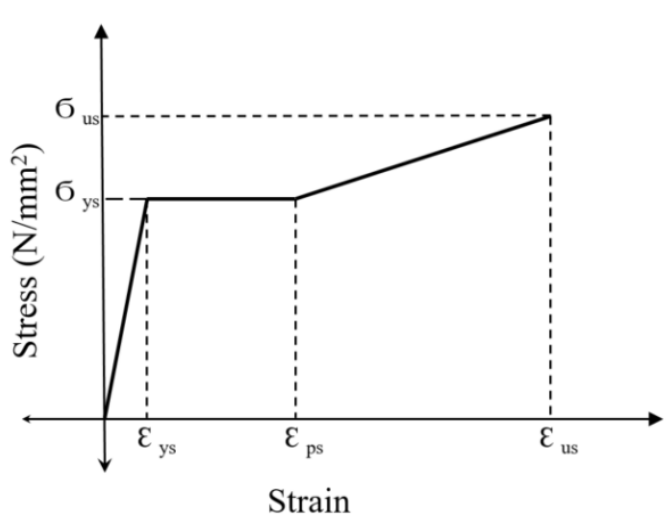

(b) Structural steel material

Fig. 24. Stress strain relationship 


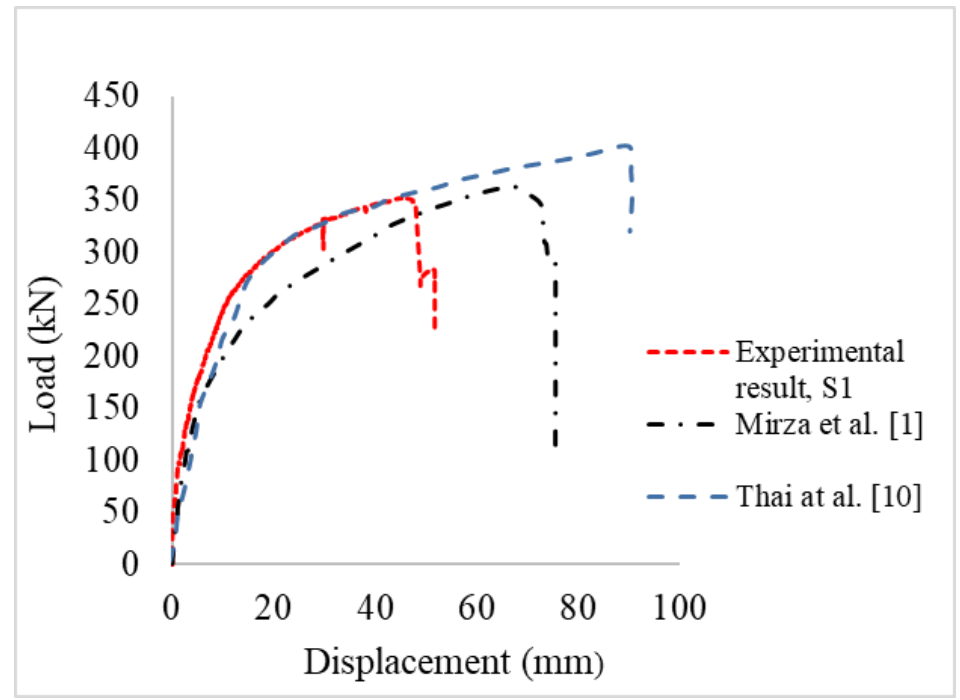

Fig. 25. Comparison of load displacement behaviour of beam-to-column flush end plate connections

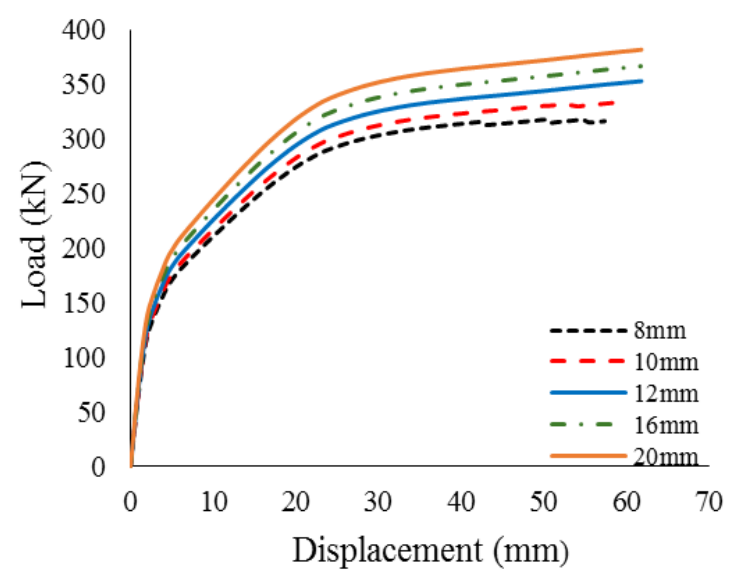

(a) $\mathrm{S} 1$

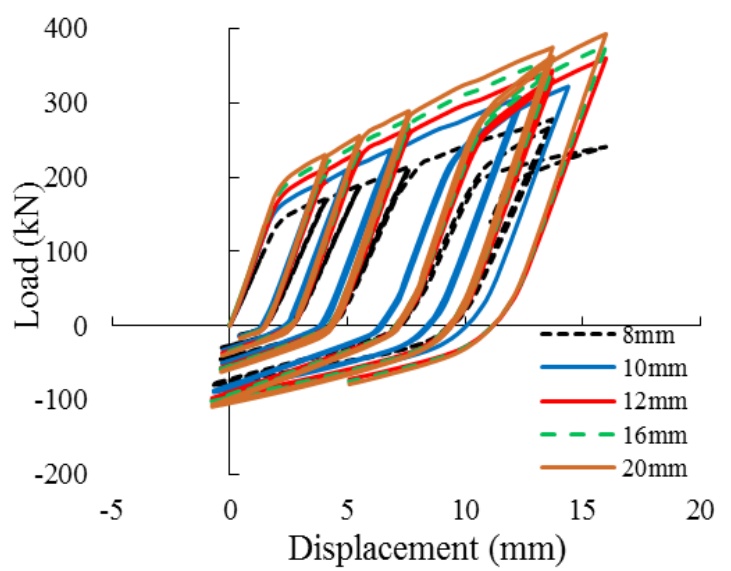

(b) S2

Fig. 26. Effect of the thickness of flush end plates 


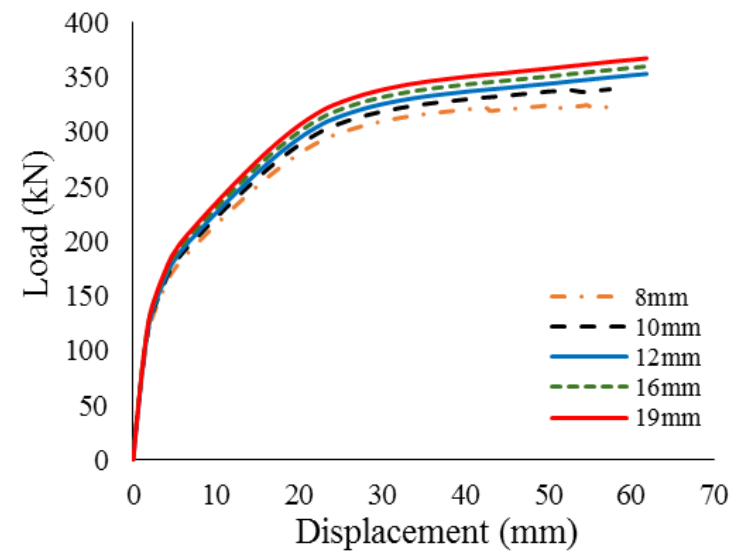

(a) $\mathrm{S} 1$

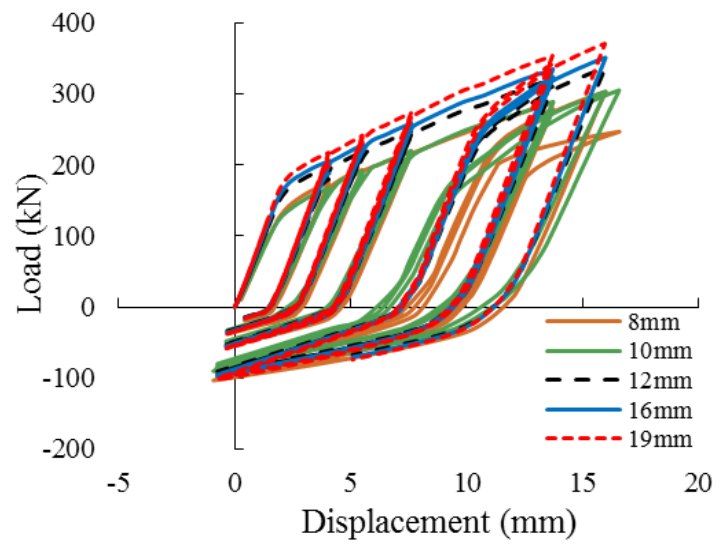

(b) S2

Fig. 27. Effect of the thickness of equal angles

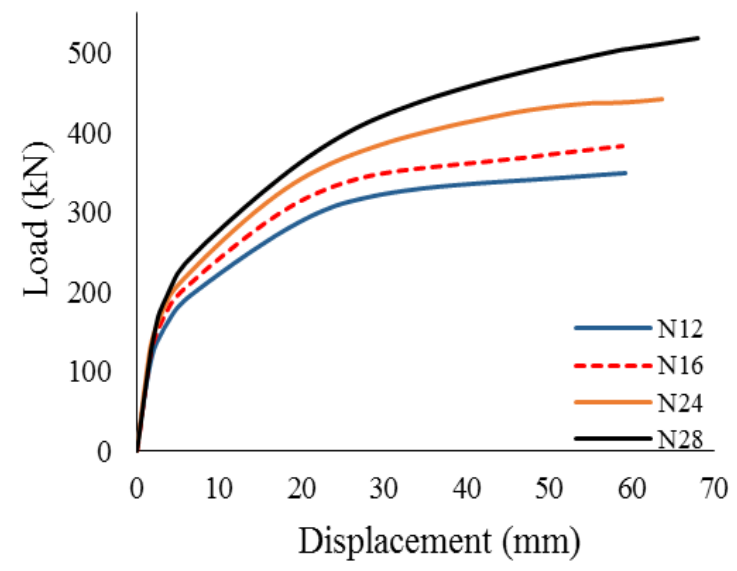

(a) S1

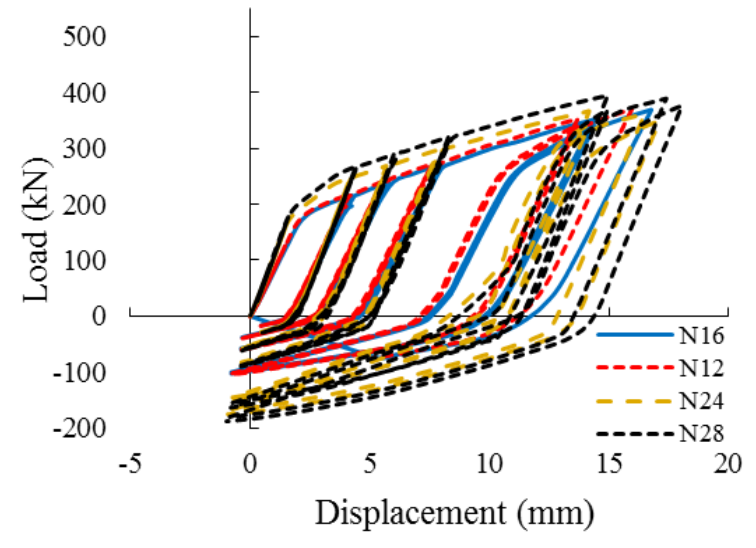

(b) S2

Fig. 28. Effect of reinforcement ratio

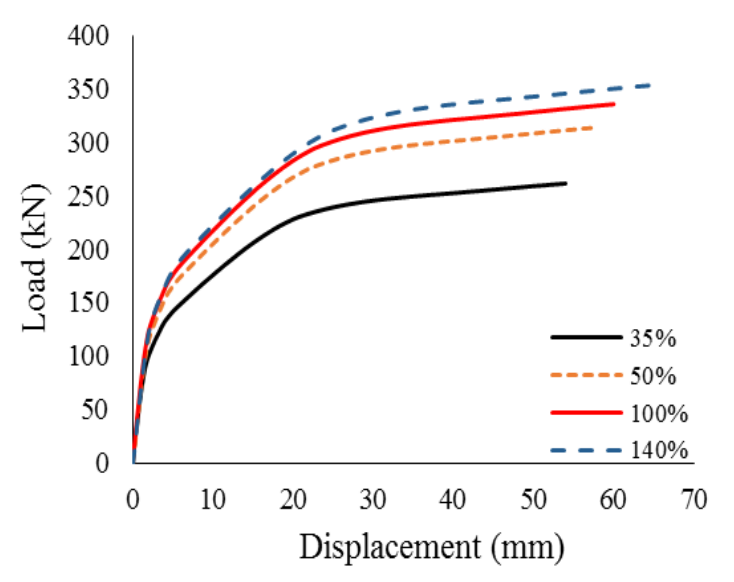

(a) S1

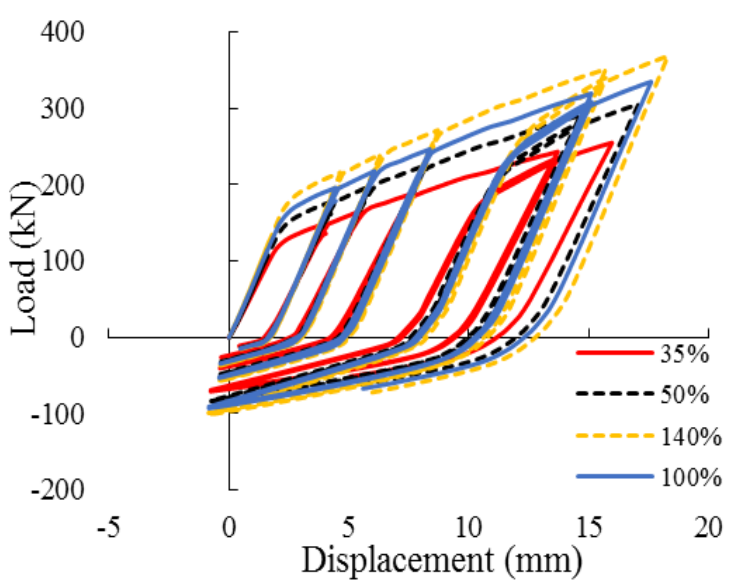

(b) S2

Fig. 29. Effect of shear connection ratio 


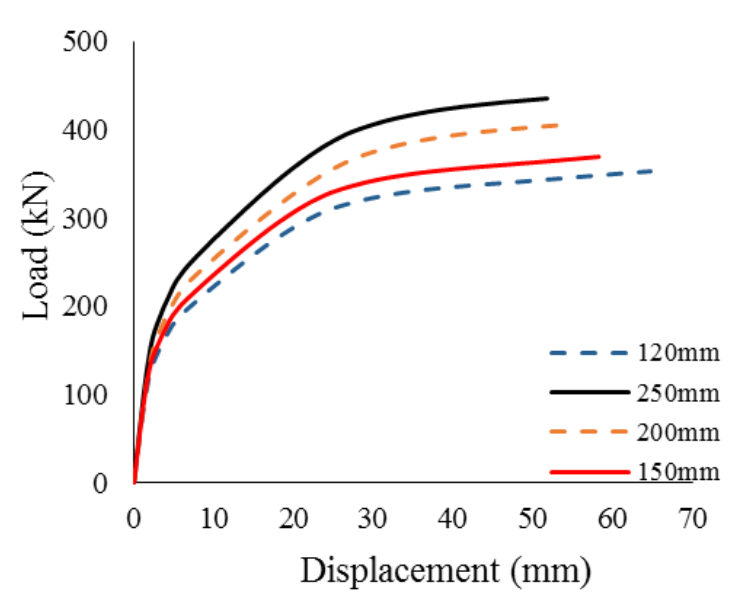

(a) $\mathrm{S} 1$

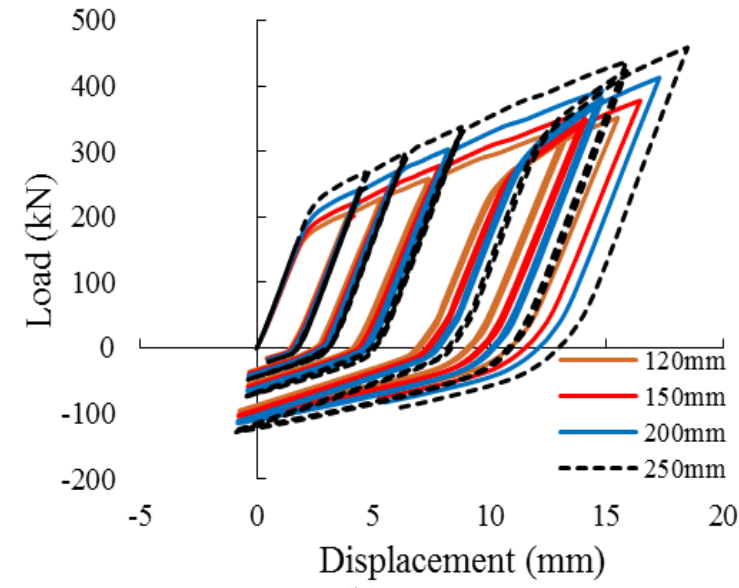

(b) S2

Fig. 30. Effect of the thickness of concrete slab 